\title{
Volver a nacer: \\ historia e identidad en los monasterios de Arlanza, San Millán y Silos (siglos XII-XIII)
}

\author{
Pilar AzcÁrate \\ Universidad Carlos III (Madrid) - SIREM \\ Julio Escalona \\ Instituto de Historia - CSIC (Madrid) - SIREM \\ Cristina JULAR \\ Instituto de Historia - CSIC (Madrid) - SIREM
}

Miguel LARRAÑAGa

Universidad SEK (Segovia) - SIREM

\begin{abstract}
RÉSUMÉ
Le Léon et la Castille constituaient deux royaumes, deux unités politiques dissemblables, dans la seconde moitié du XIt siècle (1157-1230) et c'est dans ce contexte d'écartement que la Castille envisagera une profonde révision de son passé historique, dont une des clés de voûte a été l'époque comtale et, notamment, la figure de son personnage le plus renommé, Fernán González. Le monastère de San Pedro de Arlanza a contribué d'une façon particulièrement active non seulement au développement des légendes à propos du comte mais aussi à l'utilisation de ces narrations en faveur du prestige de l'abbaye et, en même temps, en essayant de placer celle-ci au centre des processus historiques qui tentaient une nouvelle identité politique castillane, y compris une nouvelle version des origines $d u$ monastère, en préconisant, avec la falsification des textes, une fondation fictive atribuée à Fernán González. Au XIII siècle, dans le contexte de la réunification des royaumes, d'autres monastères tels San Millán de la Cogolla et Santo Domingo de Silos, prennent conscience du succès de la stratégie d'Arlanza, d'où la mise en forme d'une concurrence parmi eux pour apprivoiser la figure et les traditions du «Buen conde» et en tirer profit; une fois de plus ils ont recours aux origines, ils mettent en circulation des discours pertinents,
\end{abstract}


une fois de plus ils s'appuient sur la falsification des chartes pour construire des évidences. Le processus dont nous parlons est aussi complexe qu'une seule source ne permet pas de l'éclaircir. C'est à travers l'étude des traces d'information parsemées dans un vaste éventail de sources (chronistiques, littéraires, hagiographiques, documentaires, codicologiques) que nous essayerons de le reconstruire dans le but d'explorer les possibilités de cette approche de recherche.

\section{RESUMEN}

En la segunda mitad del siglo xiI, en el contexto de su separación del reino de León, se produjo en Castilla una intensa revisión del pasado histórico, una de cuyas claves fue la magnificación de la etapa condal y, sobre todo, de la figura de Fernán González. El monasterio de San Pedro de Arlanza parece haber jugado un papel especialmente activo, tanto en el desarrollo de las leyendas sobre el conde como en la utilización de las mismas para dar prestigio a la abadía y situarla en el centro de los procesos históricos en los que se basaba la nueva identidad política castellana, incluyendo la reformulación de sus propios orígenes, al postular, con el apoyo de la falsificación documental, una ficticia fundación por Fernán González. El éxito de la estrategia arlantina hizo que en el siglo XIII, con el trasfondo de la reunificación de los reinos, otros monasterios, como San Millán de la Cogolla y Santo Domingo de Silos, intentasen disputar a Arlanza la figura y las tradiciones del «Buen conde» y capitalizarlas en su favor, de nuevo recurriendo no sólo a reinventar sus orígenes y a poner en circulación los discursos oportunos, sino también a falsificar los documentos que pudieran apoyarlos como prueba. Es un proceso complejo que ninguna fuente por sí misma puede iluminar. Sólo es posible reconstruirlo a través del estudio combinado de los fragmentarios retazos de información dispersos en un amplio abanico de fuentes (cronísticas, literarias, hagiográficas, diplomáticas, codicológicas). Este trabajo pretende explorar las posibilidades de esta estrategia de investigación.

Este trabajo forma parte de una investigación más amplia ${ }^{1}$, que tiene por objeto estudiar cómo en la Castilla plenomedieval la revisión de la historia y la creación de nuevos discursos políticos encontraron en la falsificación documental una herramienta de la mayor importancia, y cómo el recurso a dichos elementos discursivos y la puesta en práctica de estrategias como la falsificación documental se generalizaron, convirtiéndose en un marco común dentro del cual se canalizaban la competencia política y la legitimación de las respectivas posiciones de poder. En las páginas que siguen pretendemos acercarnos a un tema que cada vez se revela con mayor fuerza como una de las claves fundamentales en dicha

1. Se trata de una investigación en equipo en la que también participa, junto con los autores de este trabajo, la Dra. Isabel Alfonso (Instituto de historia, CSIC - SIREM). 
línea de investigación: nos referimos a la importancia que se otorgó en la Castilla plenomedieval al conde Fernán González (931-970) y al uso que se hizo de dicho personaje a la hora de construir visiones del pasado y discursos de poder. Anteriormente ya habíamos sondeado la importancia de la figura de Fernán González al analizar la cuestión de la fundación del monasterio de San Pedro de Arlanza².

En esta ocasión nos centraremos en presentar las líneas maestras del proceso por el cual, entre los siglos XII y XIII, tres monasterios castellanos - San Pedro de Arlanza, San Millán de la Cogolla y Santo Domingo de Silos - utilizaron la figura del «Buen conde» y compitieron por los beneficios derivados de vincularse con el gran héroe de la independencia castellana.

\section{Reinventar la Castilla condal}

Todavía estamos muy lejos de comprender plenamente las razones por las que los reinos de León y Castilla se separaron a la muerte de Alfonso VII (1157), pero todo sugiere que esto dio lugar a una situación peculiar para el naciente reino castellano en el plano de la identidad histórica. Castilla había sido originariamente un condado del reino leonés - por más que hubiese gozado de cierta autonomía en la segunda mitad del siglo x, la independencia de la Castilla condal es en gran medida una ficción plenomedieval - y sólo tuvo la condición de reino independiente de manera fugaz bajo Fernando I y ya de forma consolidada durante el breve reinado de Sancho II (1065-1072). Pese a la creciente importancia estratégica e ideológica de Toledo tras su conquista en 1085, León siguió siendo el corazón político y simbólico de una monarquía de supuesto origen visigodo. La ciudad regia era la sede por excelencia del imperium hispánico, noción que servía de vehículo al ideal neogoticista de hegemonía peninsular, por irreal y anacrónica que esta aspiración fuese en los siglos XI y XII.

Hasta la muerte de Alfonso VII el pasado histórico castellano iba unido al del reino de León y a su dinastía reinante, pero entre 1157 y 1230 la situación cambió notablemente. En términos estrictamente genealógicos, los lazos de sangre que vinculaban a los monarcas castellanos con sus parientes leoneses les permitían compartir la misma legitimidad y el mismo glorioso pasado. Pero no ocurría lo mismo con su reino. Por lo

2. Julio Escalona y Pilar AzcÁrate, «Una fuente "casi” perdida para la historia de la Castilla medieval. Notas en torno al Becerro de Arlanza», Hispania, 208, 2001, p. 474-449; Julio Escalona, Pilar Azcárate y Miguel Larrañaga, «De la crítica diplomática a la ideología política. Los diplomas fundacionales de San Pedro de Arlanza y la construcción de una identidad para la Castilla medieval», in: VI congreso internacional de Historia de la cultura escrita, 2 t., Madrid: Calambur, 2002, t. 1, p. 159-206. 
que a la reverenda tradición escrituraria respectaba, Castilla carecía de una memoria escrita que le proporcionara una identidad histórica propia diferenciada de León. Hasta el siglo XIII - y con la sola excepción de un puñado de piezas de tipo analístico - la escasa producción historiográfica del noroeste peninsular se alineaba claramente con la identidad política y los intereses de la monarquía leonesa. De hecho, en textos como la Crónica de Alfonso III (fines del siglo IX) o la Crónica de Sampiro (ca 1020) es difícil encontrar una sola referencia a Castilla que no sea, bien una expresión de su sometimiento al poder de los reyes de Oviedo/León, o bien una denigración de su carácter rebelde. A mediados del XII no era, pues, posible recurrir a los prestigiosos textos de la tradición cronística leonesa en busca de elementos legitimadores de un pasado histórico respetable para una Castilla diferenciada de León ${ }^{3}$.

Gracias en gran medida al monumental trabajo de Georges Martin sobre la leyenda de los Jueces de Castilla ${ }^{4}$, podemos ahora entrever que, en este contexto, se produjo en Castilla una revisión del pasado basada, a falta de textos, en fuentes orales de carácter épico y legendario. Un conjunto heterogéneo de viejas narraciones, mezcladas con otras nuevas, se fueron entretejiendo hasta componer un corpus integrado susceptible de ser utilizado como sustituto de la historia cronística que a Castilla le faltaba ${ }^{5}$. Simplificando mucho, y dejando de lado otras tradiciones relacionadas con León y con la temática carolingia, podemos dividir lo esencial del corpus épico castellano en dos $\operatorname{ciclos}^{6}$ :

3. Las crónicas del siglo XII, como la mal llamada Historia silense, la Historia compostelana o la Crónica del obispo pelayo comparten el mismo carácter proleonés y hostil a lo castellano. La única excepción es la Chronica Adefonsi imperatoris, un texto que, a pesar de que se haya insistido en su leonesismo a causa de la lealtad del anónimo autor hacia la figura del emperador leonés, muestra un interés fundamental por las cuestiones castellanas y muy especialmente por Toledo. Ver Julio Escalona, «Misericordia regia, es decir, negociemos. Alfonso VII y los Lara en la Chronica Adefonsi imperatoris», in: Isabel Alfonso, Julio Escalona, Georges MarTin (ed.), Lucha política. Condena y legitimación en la España medieval, Lyon: ENS Éditions (Annexes des Cahiers de linguistique et de civilisation hispaniques médiévales, 16), 2004, p. 101-152.

4. Georges Martin, Les juges de Castille. Mentalités et discours historique dans l'Espagne médiévale, París: Klincksieck (Annexes des Cahiers de linguistique hispanique médiévale, 6), 1992.

5. Pero no era realmente historia del tipo que se podía leer en las crónicas. Esto se manifiesta claramente en las dificultades con que toparon en el siglo XIII los compiladores del taller alfonsí que trabajaban en la Estoria de España a la hora de conciliar los materiales épicos con la tradición escrita historiográfica, sobre todo en el tramo del siglo XI. Así se explica el frenazo de la Versión primitiva a la muerte de Vermudo III y el esfuerzo de la Versión crítica por reordenar cronológicamente las inserciones de material épico, véase Inés FERNÁNDEZ-ORDóñEz, «El taller de las Estorias», in: Inés Fernández-Ordóñez (ed.), Alfonso X el Sabio y las Crónicas de España, Valladolid: Fundación Santander central hispano - Centro para la edición de los clásicos españoles, 2000, p. 61-82, en p. 74-76; Mariano DE LA CAMPA, «Las versiones alfonsíes de la Estoria de España», ibid., p. 83-106, en p. 85 y sq., y 93 у sq.

6. Louis Chalon, L'histoire et l'épopée castillane du Moyen Âge. Le cycle du Cid. Le cycle des comtes de Castille, París: Champion, 1976. 
a) El ciclo del Cid Campeador, en el que la narración de las gestas de Rodrigo Díaz de Vivar servía de leit motiv para componer una visión de las tensiones entre Castilla y León, con el transfondo de la muerte de Sancho II y la absorción de su reino por el monarca leonés Alfonso VI. Las narraciones de esta temática específica, como el Cerco de Zamora, acabaron imbricándose con la historia del Cid, todo lo cual permitía cubrir con una narrativa pseudohistórica la segunda mitad del siglo XI. En este trabajo prescindiremos de todo este ciclo, para centrarnos en la etapa histórica precedente.

b) El ciclo de los Condes de Castilla, en realidad un conjunto heterogéneo de historias de muy diferente procedencia y carácter, que acabaron siendo sistematizadas y ordenadas para componer una narrativa histórica ajustada a la sucesión dinástica de los condes castellanos. Así, el extraño y ucrónico relato de los Jueces de Castilla, con su poderoso rechazo de lo leonés, se fundió con las gestas de los condes, empezando por la figura casi íntegramente ficticia de un Fernán González presentado como el anacrónico fundador de un condado de Castilla independiente de León. Otras narraciones, convenientemente manipuladas, permitieron dotar de sus propias personalidades histórico-narrativas a los sucesores de Fernán González. Gracias a su ubicación en el contexto de la época de García Fernández y a la introducción del conde como personaje de la historia, la «Leyenda de los infantes de Lara» - a su vez probable amalgama de relatos de diferente procedencia- cobra un valor más general: asociar el dramatismo de la historia a la trayectoria del propio conde, y añadir estas estampas a las de la narración de la «Condesa traidora». El ciclo se remata brillantemente con la tragedia de la muerte del infante García, que permite cerrar la historia de la época condal con un alegato anti-leonés por la extinción de la dinastía de Fernán González.

La tarea de ubicar en el tiempo la aparición de estas narraciones - de carácter primordialmente oral y con testimonios textuales escasos y tardíos - se muestra en toda su dificultad una vez superada la visión historicistatradicionalista de la épica castellana abanderada por Menéndez Pidal', que les suponía un desarrollo más o menos complejo, a partir de un origen inmediato a los hechos narrados. En Castilla, el primer testimonio narrativo sustancial se produce en fecha tan tardía como la década de los años 80 del siglo XII, cronología que se viene proponiendo últimamente para la llamada Crónica najerense ${ }^{8}$. En este complejo y abigarrado texto encontramos ya retazos, aunque muy fragmentarios, de buena parte de las narraciones de los ciclos épicos castellanos, especialmente las historias de los Jueces de

7. Sobre todo en Ramón Menéndez Pidal, Reliquias de la poesía épica española, Madrid: EspasaCalpe, 1951 y Ramón Menéndez Pidal, La leyenda de los infantes de Lara (3 ${ }^{\mathrm{a}} \mathrm{ed}$.), Obras completas, t. I, Madrid: Espasa-Calpe, 1971.

8. Juan A. Estévez Sola (ed.), Chronica naierensis, Turnhout: Brepols, 1995 (Corpus christianorum. Continuatio mediaevalis, $71 \mathrm{~A}$ ), p. LXx y sq. Téngase además en cuenta el valor del testimonio paralelo del Liber regum navarro, cuyo arquetipo data G. MARTIN en el último cuarto del siglo XiI: G. Martin, Les juges de Castille..., p. 46-82. 
Castilla, de Fernán González y del Cid Campeador. La Najerense apenas hace otra cosa que transmitir referencias brevísimas que remiten a dichos relatos, pero es posible que eso sea precisamente lo más revelador, puesto que demuestra que las narraciones a las que se alude eran referentes suficientemente conocidos para los potenciales receptores del texto, de manera que el autor no necesitaba extenderse en ello. Se daba por hecho que la audiencia contaba con las claves para comprender el mensaje. Más aún, en la Crónica Najerense, los diferentes relatos aparecen ya entrelazados por medio de la herramienta más obvia de que dispone un autor medieval, experto en la redacción del tipo de historia en que las gestas de las individualidades egregias dominan la escena: la genealogía. En efecto, en la Najerense los pedigrees de las diferentes casas reinantes se pueblan con toda naturalidad de reyes godos, jueces de Castilla, Fernán González y el Cid Campeador. Esta es la mejor prueba de que, a la altura de los años 80 del siglo XII, las narraciones épicas sobre la Castilla de los siglos X y XI se habían interconectado y entretejido hasta formar precisamente el sucedáneo de un prestigioso pasado histórico que el reino de Castilla necesitaba.

En el presente estado de la investigación apenas podemos hacer otra cosa que preguntarnos por qué un desarrollo de esta envergadura no dio lugar a la redacción, en la Castilla de la segunda mitad del siglo XII, de una obra cronística de entidad comparable a la Historia compostellana o a la Chronica Adefonsi imperatoris ${ }^{9}$. Por supuesto, cabe la posibilidad de que se escribiese alguna obra de este tipo, pero que no alcanzase la difusión necesaria ${ }^{10}$. En todo caso, para ver a la épica castellana generar desarrollos historiográficos de auténtico peso, tenemos que esperar hasta 1230, cuando en el contexto histórico de la reunificación de los reinos, las relaciones entre Castilla y León volvieron a convertirse en asunto de la máxima importancia política. El resultado fue un auténtico boom historiográfico, con la redacción casi simultánea en la década siguiente, de tres grandes crónicas latinas: el Chronicon mundi de Lucas de Tuy, el De rebus Hispaniae de Rodrigo Jiménez de Rada y la anónima Crónica latina de los reyes de Castilla ${ }^{11}$.

9. Peter Linehan, «Lucas de Tuy, Rodrigo Jiménez de Rada y las historias alfonsíes» in: I. Fernández-Ordóñez (ed.), Alfonso X el Sabio, p. 19-36, en p. 19-21.

10. No se olvide que algunas de las crónicas de este período surgieron en contextos muy específicos y no entraron en la corriente principal de transmisión del conocimiento histórico que desemboca en Jiménez de Rada y en el círculo cortesano de Alfonso X, como parece haber ocurrido con la Chronica Adefonsi imperatoris.

11. Ediciones: Emma Falque (ed.), Chronicon mundi Lucae Tudensis, Turnhout: Brepols, 2003 (Corpus christianorum, 74. Continuatio mediaevalis); Juan Fernández Valverde (ed.), Roderici Ximenii de Rada Historia de rebus Hispaniae sive historia gothica, Turnhout: Brepols, 1987 (Roderici Ximenii de Rada Opera omnia, 1); Luis Charlo Brea, Juan A. Estévez Sola y Rocío Carande Herrero (ed.), Chronica hispana: saeculi XIII, Turnhout: Brepols, 1997 (Corpus christianorum. Continuatio mediaevalis, 73). Sobre estas crónicas, ver Ana RoDRÍGUEz LóPEz, «Sucesión regia y legitimidad política en Castilla en los siglos XII-XIII. Algunas consideraciones sobre el relato 
La convergencia de Castilla y León - para contrariedad de Lucas de Tuy, sin duda - distó mucho de ser un retorno al estado de cosas anterior a 1157, es decir, al imperium leonés. En la Corona de Castilla reunificada - y esto es algo que también está aún lejos de haber sido explicado satisfactoriamente - la hegemonía no correspondía a León, sino a una Castilla cuyo centro tradicional había sido Burgos, pero que ahora tenía su foco simbólico principal en Toledo ${ }^{12}$. En este contexto, el corpus castellano de narraciones pseudo-históricas tenía una función renovada que cumplir. Si en origen su destino había sido proveer la identidad histórica diferenciada de León que Castilla necesitaba, ahora era preciso utilizarlas para construir un discurso histórico común, pero en el que la parte castellana pudiese equilibrar la poderosa tradición cronística asturleonesa y, en último término, avalar un presente dominado por Castilla. Así se explica que la magna crónica de Lucas de Tuy, demasiado escorada hacia el lado leonés, fuera inmediatamente sustituida por la no menos monumental de Rodrigo Jiménez de Rada. De rebus Hispaniae utiliza una cantidad importante de temas procedentes de la tradición épico-histórica de Castilla para construir un discurso en el que el pasado castellano brilla con luz propia, frecuentemente sin escatimar expresiones cargadas de agresividad hacia León ${ }^{13}$. El proceso culmina en la segunda mitad del siglo XIII, con la redacción de las grandes obras historiográficas del taller alfonsí. La Estoria de España no sólo incorpora un repertorio más amplio de temas épicos, sino que además su carácter vernáculo le permite insertar de manera casi directa amplios pasajes que no son sino prosificaciones de las narraciones poéticas, como el cotejo con los textos poéticos conservados revela.

Por lo tanto, la primera imagen comprehensiva del corpus pseudohistórico castellano, y la mejor muestra de su valor para componer un discurso de legitimación política basado en una ficción del pasado, surge a partir de la cronística alfonsí. Una generación antes, y de manera menos explícita, Jiménez de Rada muestra lo esencial de ese corpus en funcionamiento con fines parecidos. A fines del siglo XII, la Najerense prueba que lo fundamental del corpus existía ya y estaba ampliamente divulgado. En estos tres jalones, la figura de Fernán González ocupa un lugar de

de las crónicas castellano-leonesas», in: I. Alfonso, J. Escalona y G. MarTin (ed.), Lucha politica..., op. cit. Agradecemos a la autora habernos permitido utilizar el texto de su trabajo en curso de publicación.

12. Peter LineHan, History and the Historians of Medieval Spain, Oxford: Clarendon Press, 1993, p. 287 y $s q$. Los intentos de refundar una primacía eclesiástica toledana de estirpe visigoda sobre la totalidad de la Península no pueden ser separados de este proceso general. Ver Patrick Henriet, «Political Struggle and the Legitimation of the Toledan Primacy: the Pars Lateranii Concilii», in: Isabel Alfonso, Hugh KenNedy y Julio Escalona, Building Legitimacy: Political Discourses and Forms of Legitimation in Medieval Societies, Leiden - Boston: Brill, 2004, p. 291-318.

13. De rebus Hispaniae, V, 2. 
preferencia como padre de la Castilla independiente. Sin embargo, no es posible determinar a partir de ellos con precisión cuándo esta nueva visión legendaria del conde castellano creció y se impuso sobre el personaje conocido por los diplomas del siglo x o por la Crónica de Sampiro.

Por otra parte, las obras de tipo cronístico, a menudo procedentes de los círculos más próximos a la monarquía, no pueden dar una imagen cabal de cómo este tipo de actitudes hacia el pasado se desenvuelven en otros contextos sociales. Podemos, no obstante, hacer un ensayo en esta dirección, centrando la atención en los entornos monásticos. Sabemos que las principales abadías benedictinas castellanas buscaron establecer lazos estrechos con las figuras más relevantes del universo épico, presentándose como objeto preferencial de su devoción, o bien como escenario de sus gestas, o, muy especialmente, fomentando la veneración de sus enterramientos, ya fuesen auténticos o pretendidos. Es notoria la predilección de San Salvador de Oña por las figuras del conde Sancho García y su hijo el infante García, o la de san Pedro de Cardeña por García Fernández y el Cid, o, sobre todo, la relación establecida entre Arlanza y Fernán González. Carlos Alvar ${ }^{14}$ tiene probablemente razón al advertir que los monasterios difícilmente pudieron dar origen a las tradiciones épicas: éstas tuvieron que desarrollarse de manera autónoma - lo que no excluye la participación monacal - hasta alcanzar un prestigio y una difusión capaces de dar sentido a su instrumentalización por parte de los monasterios. Este tipo de desarrollo es, en todo caso, una línea muy difícil de seguir.

En cambio, es posible sondear otro aspecto crucial, hasta ahora insuficientemente investigado: la competencia por capitalizar la temática épica, lo que es un buen indicador de su aceptación social como elemento legitimador. Desde esta perspectiva vamos a estudiar la pugna por el uso de la figura de Fernán González entre Arlanza, San Millán y Silos. Para ello nos parece insuficiente —incluso distorsionador - limitarse al estudio de una sóla fuente o tipo de fuentes. Por ello, hemos optado por sondear, para cada uno de esos tres monasterios, cuatro ejes que son otras tantas estrategias en la búsqueda de una interpretación unitaria a partir de una información extraordinariamente fragmentada:

a) En primer lugar, sin duda, hay que considerar las fuentes literarias, tanto las obras cronísticas como el género hagiográfico, específicamente clerical.

b) En segundo lugar consideraremos la falsificación documental cuando ésta tiene por objeto modificar la memoria histórica del monasterio para vincularlo con Fernán González.

14. Carlos Alvar, «Estudio introductorio», in: Manuel Alvar (ed.), Épica española medieval, Madrid: Editora nacional, 1981, p. 57. 
c) En tercer lugar, incluiremos en el análisis una estrategia diferenciada $-\mathrm{y} \mathrm{a}$ menudo pasada por alto - como es el solicitar y obtener de la cancillería regia privilegios confirmatorios de los diplomas falsos. Esta práctica supone legitimar el falso - a veces, incluso, reemplazarlo - con la creación de un nuevo original de plena validez jurídica, que viene a darle fuerza renovada, especialmente en la arena judicial.

d) Finalmente, tendremos en cuenta los procesos de redacción y alteración de los cartularios monásticos, cuando éstos se relacionan con diplomas falsos del tipo antes citado.

Sin pretender establecer un orden cronológico entre ellos, ni dar mayor valor interpretativo a uno u otro, podemos distribuir estos cuatro ejes en una matriz sobre la que comparar los tres monasterios estudiados:

\begin{tabular}{|l|l|l|l|}
\hline & Arlanza & San Millán & Silos \\
\hline Literatura & & & \\
\hline Falsificación documental & & & \\
\hline Confirmación regia & & & \\
\hline Cartulario & & & \\
\hline
\end{tabular}

Se trata, en cualquier caso, de una exploración preliminar, dado que las vías para profundizar en el estudio de este tema son notablemente complejas y la tarea está apenas iniciada. En estas páginas presentaremos las líneas maestras de la investigación, las estrategias metodológicas propuestas y las nuevas perspectivas de trabajos que esperamos desarrollar en el futuro.

Antes de iniciar el análisis, es preciso considerar la posición relativa de los tres monasterios. Ubicado en el corazón de la Tierra de Lara, al pie de las elevaciones de la Sierra de la Demanda, Arlanza fue un cenobio de cierta importancia en época condal, en que inició la creación de su dominio monástico con el apoyo de varios magnates castellanos, Fernán González entre ellos. Sin embargo, su verdadera expansión tuvo lugar durante el reinado de Fernando I, quien potenció enormemente su dominio y lo elevó al plano de principal monasterio de la Tierra de Lara y, en general, del sector castellano al sudeste de Burgos ${ }^{15}$ (en el entorno de la ciudad, San

15. Sobre todo ello, ver Julio Escalona, Sociedad y territorio en la alta Edad Media castellana. La formación del Alfoz de Lara (British Archaeological Reports, International Series, 1079), Oxford: John and Erica Hedges, 2002. Sobre el dominio monástico de Arlanza en la Edad Media, ver Carmen LEÓN-Sotelo CASADO, «Formación y primera expansión del dominio monástico de San Pedro de Arlanza (siglo x)», En la España Medieval (Estudios dedicados al prof. D. Julio González González, t. 1), 1, 1980, p. 223-235; Carmen León-Sotelo CaSAdo, «La expansión del 
Pedro de Cardeña siempre tuvo un desarrollo e importancia muy superior). Por su parte, el monasterio riojano de San Millán de la Cogolla, en la vertiente opuesta de la cordillera Ibérica, es una fundación de época visigoda, que conoció una discreta trayectoria durante la alta Edad Media hasta su expansión desde mediados del siglo x. En el siglo XII se convertirá en la principal abadía benedictina de una Rioja incorporada a Castilla y, a la sazón, en uno de los monasterios clave del reino, con un dominio señorial inmenso, y capaz en el siglo XIII de enzarzarse en complejas disputas jurisdiccionales con concejos urbanos y obispados ${ }^{16}$. Finalmente, Santo Domingo de Silos, vecino próximo de Arlanza, es el otro gran monasterio del sudeste castellano. De trayectoria incierta en época conda ${ }^{17}$, su despegue se sitúa también en tiempos de Fernando I, pero sólo a partir de Alfonso VI tiene lugar su elevación a un primer plano en el contexto castellano, gracias, sobre todo, a la capitalización del culto en torno al enterramiento del abad Domingo y a la fama de lugar milagroso que desde entonces se desarrolló ${ }^{18}$. Santo Domingo de Silos creció en competencia con Arlanza. Sus dominios señoriales y sus áreas de expansión - y de captación de potenciales peregrinos - se solapaban. Así, no es raro que sus intereses entrasen en conflicto más de una vez entre los siglos XII y XIII, como testimonian varios procesos judiciales conservados entre la documentación de ambas instituciones. Esta pugna se reprodujo, como veremos, en el plano ideológico y discursivo.

No debe pasarse por alto que, a lo largo del período clave que nos interesa (de mediados del siglo XII a mediados del XIII), San Millán y Silos parecen haber formado una alianza estable frente a Arlanza. La vinculación entre ambos monasterios se remonta a la propia época del abad Domingo, monje procedente de San Millán, y continúa con intercambios fundamentales como el propio Grimaldo, autor de la Vita latina de Santo Domingo,y quizá monje en San Millán antes de ingresar en

dominio monástico de San Pedro de Arlanza a lo largo del siglo XI», En la España medieval (Estudios en memoria del profesor D. Salvador de Moxó, t. 1), 2, 1982 p. 573-582; Carmen LEónSotelo Casado, «El dominio monástico de San Pedro de Arlanza durante la plena y baja Edad Media», En la España medieval (Estudios dedicados al profesor D. Ángel Ferrari Núñez, t. 1), 4, 1984, p. 499-511. Sobre la proyección señorial de Arlanza, ver Ignacio Álvarez Borge, Poder y relaciones sociales en Castilla en la Edad Media. Los territorios entre el Arlanzón y el Duero en los siglos $X$ al XIV, Salamanca: Junta de Castilla y León, 1996, p. 111-113.

16. José Ángel García de Cortázar, El dominio del monasterio de San Millán de la Cogolla (siglos $x$ al XIII). Introducción a la historia rural de Castilla altomedieval, Salamanca: Universidad de Salamanca, 1969.

17. J. Escalona, Sociedad y territorio..., p. 197 y sq.

18. Sobre la expansión señorial de Silos, ver Magdalena Ilardia, El dominio monástico de la abadía de Santo Domingo de Silos (954-1214), Memoria de licenciatura inédita, Universidad de Deusto, 1974; y Juan José García GonzÁlez, «El dominio del monasterio de Santo Domingo de Silos (954-1214)», in: El románico en Silos. IX Centenario de la consagración de la iglesia y el claustro, Santo Domingo de Silos: Abadía de Silos, 1990, p. 31-67. 
Silos ${ }^{19}$. Es más, la circunstancia se repite a comienzos del siglo XIII con Gonzalo de Berceo, como veremos. Esta vinculación es además explícita en la hermandad establecida entre ambos monasterios en 1190 y renovada en $1236^{20}$. En el punto culminante del proceso que estudiamos, pues, San Millán y Silos formaban una unidad estratégica, lo que puede explicar algunas de las concomitancias observables entre ambos. San Pedro de Arlanza parece haber dado el primer paso en la carrera por apropiarse de la figura de Fernán González. A ello sucedieron iniciativas parecidas por parte de San Millán y Silos, en este orden.

\section{San Pedro de Arlanza se reinventa a sí mismo}

\section{Literatura}

La formulación más explícita de la relación entre Arlanza y el Buen conde es, sin duda, el llamado Poema de Fernán González, una larga composición en cuaderna vía en que la presencia del monasterio aparece cuidadosamente entretejida con la historia del conde. Fernán González no sólo figura como fundador y favorecedor de la abadía, sino que ésta desempeña un papel providencial en el desarrollo de sus gestas, que incluyen el desplazamiento a la comarca de Lara de los principales hitos épicos (batallas de Lara, Hacinas y Cascajares). Igualmente, algunos pasajes muestran imbricaciones de tipo genealógico con la otra gran pieza épica de la comarca de Lara, la Leyenda de los Infantes de Lara ${ }^{21}$. Aunque la cronología del Poema está sujeta a debate, se mueve en un arco entre los años 1250 y $1280^{22}$, lo que lo sitúa al final del período que estamos considerando, en consonancia con la inserción de abundantes fragmentos de su texto en la

19. Véase Vitalino Valcárcel (ed.), La «Vita dominici siliensis» de Grimaldo. Estudio, edición crítica y traducción, Logroño: Instituto de estudios riojanos, 1982, p. 89 y sq.

20. Miguel Carlos Vivancos Gómez, Documentación del monasterio de Santo Domingo de Silos: (954-1254), Burgos: J. M. Garrido, 1988, doc. 77 y 131.

21. Concretamente, se trata de la presencia entre los vasallos del conde de un Gustios González de Salas, abuelo de Gonzalo Gustios, el legendario padre de los infantes de Salas (luego de Lara), véase Julio EscalonA, «Épica, crónicas y genealogías. En torno a la historicidad de la leyenda de los infantes de Lara», Cahiers de linguistique hispanique médiévale, 23, 2000, p. 113-176.

22. Aunque el debate se remonta a Marden y Menéndez Pidal, en fechas más recientes las principales opiniones se dividen entre quienes proponen dataciones oscilantes entre 1275 y 1285, como María Eugenia LaCARra, «El significado histórico del Poema de Fernán González», Studi ispanici, 1979, p. 9-41; oJ. P. KeLLer, The Poet's Myth of Fernán González, Maryland, 1990, p. 92-105, y las de aquellos que defienden fechas más tempranas, dentro de la década de los 50: Miguel Ángel Muro Munilla, Poema de Fernán González, Logroño: Instituto de estudios riojanos, 1994, p. 14; e Itzíar López Guil, Libro de Fernan Gonçalez, Madrid: CSIC, 2001, p. 25-36 (con referencias a las aportaciones anteriores). 
Estoria de España, que claramente, consagra una visión pro-arlantina de la gesta del conde.

Aunque sea la formulación más completa y detallada —o quizá precisamente por serlo-, el Poema de Fernán González debe ser visto no como un punto de partida, sino como el punto de llegada de una línea argumental que venía gestándose desde antes. Rastreando hacia atrás, sin embargo, llama inmediatamente la atención la referencia proporcionada por $D e$ rebus Hispaniae, II, V, donde Jiménez de Rada inicia su lista de las fundaciones y lugares de enterramiento de los condes castellanos precisamente con Fernán González, de quien dice que fundó el monasterio de Arlanza y en él se enterró. Es claro que mucho antes de la redacción del Poema de Fernán González la relación entre el conde y la abadía estaba tan firmemente establecida que podía ser incorporada a una narración histórica de carácter general como algo ampliamente sabido y aceptado.

Con anterioridad a la década de los años 40 del siglo XIII, sin embargo, buscaremos en vano en las fuentes literarias muestras de una conexión entre Arlanza y Fernán González. La Najerense menciona diversos aspectos de la gesta del conde, probando que ya existía y era ampliamente conocida hacia 1180, pero su anónimo autor omite toda relación con Arlanza, quizás porque carece de interés para sus objetivos, que son sobre todo de naturaleza genealógica. Sin embargo esto no quiere decir que la conexión entre Arlanza y el conde se desarrollase entre los 1180's y los 1240's; de hecho, parece haber sido mucho más antigua.

\section{Falsificación documental}

En este punto es preciso cambiar de enfoque y sondear el terreno de la falsificación documental. Este aspecto ha sido objeto de dos publicaciones recientes por parte de nuestro equipo, de manera que aquí nos limitaremos a aportar los detalles necesarios para la línea argumental que desarrolla$\operatorname{mos}^{23}$. Arlanza contaba con un documento fundacional datado en 912, a cargo del conde Gonzalo Téllez de Lantarón, un personaje de gran importancia en la Castilla de comienzos del siglo x, emparentado con la familia materna de Fernán González ${ }^{24}$. Sin embargo, a la altura del siglo XII, Gonzalo Téllez había sido olvidado casi por completo, con lo que una fundación a su nombre poco aportaba al prestigio de la abadía. En vista

23. J. Escalona y P. Azcárate, «Una fuente "casi” perdida...»; J. Escalona, P. Azcárate y M. LARRAÑAGA, «De la crítica diplomática a la ideología política...».

24. Iñaki Martín VISO, «Poder político y estructura social en la Castilla altomedieval: el condado de Lantarón (siglos VIII-XI)», in: José Ignacio De La IgLesia Duarte (coord.), Los espacios de poder en la España medieval. XII semana de estudios medievales de Nájera, Logroño: Instituto de estudios riojanos, 2002, p. 533-552. 
de ello, los monjes arlantinos optaron por falsificar un nuevo documento fundacional, compuesto a imitación del auténtico hasta en la caligrafía, y con muy pocas variaciones en su contenido, del que mantenía incluso la data de 912, congruente con la época de Gonzalo Téllez pero imposible para Fernán González. El análisis de esta falsificación documental, tanto a través de sus datos internos como por contraste con otros documentos del fondo arlantino, nos ha permitido establecer que el diploma falso debió de ser elaborado en el tercer cuarto del siglo xII, más bien hacia su comienzo que al final, sin excluir la posibilidad de que se realizase incluso antes de la muerte de Alfonso VII ${ }^{25}$. Es poco probable que un diploma de este tipo sea el punto de inicio de la tradición sobre la fundación de Arlanza por Fernán González; parece más plausible que el documento se cree para respaldar una idea preexistente y con cierta circulación, pero que ahora se quiere apoyar documentalmente, entre otras cosas, para obtener ventajas judiciales ${ }^{26}$. Para ajustar mejor la cronología, sin embargo, es preciso atender a otras fuentes de información.

\section{Obtención de privilegio confirmatorio}

Cuando, a mediados del siglo XIII, se generalizó la práctica de solicitar de la cancillería regia confirmaciones in extenso de documentos anteriores, en previsión de su deterioro o destrucción ${ }^{27}$, Arlanza no tardó en seguir esta vía. En 1255, un año clave para Castilla, en general, y para la comarca de Lara en particular ${ }^{28}$, solicitó del rey Alfonso X la confirmación de las piezas más relevantes de su archivo, entre ellas, por supuesto, el falso diploma fundacional. Con ello, la falsificación se vio refrendada por el poder regio y revestida de una legitimidad adicional, sumamente conveniente a la hora de pleitear, como se constata a lo largo de la baja Edad Media y durante toda la Edad Moderna.

25. J. Escalona, P. Azcárate y M. Larrañaga, «De la crítica diplomáica a la ideología política...», p. 186.

26. Sobre las dimensiones judiciales de la falsificación, ver ibid., p. 181-182.

27. José Antonio Fernández Flórez, La Elaboración de los documentos en los reinos hispánicos occidentales (siglos VI-XIII), Burgos: Institución Fernán González, 2002, p. 135-137; Julio Escalona, «Lucha política y escritura. Falsedad y autenticidad documental en el conflicto entre el monasterio de Santo Domingo y el burgo de Silos (siglos XIII-XIV)», in: José Ignacio DE LA IGLesia DuARTE (ed.), Conflictos sociales, políticos e intelectuales en la España de los siglos XIV y XV. XIV semana de estudios medievales de Nájera, Logroño: Instituto de estudios riojanos, 2004.

28. Gonzalo Martínez Díez (ed.), Leyes de Alfonso X. II: Fuero Real, Ávila: Fundación Sánchez Albornoz, 1988, p. 107 y sq.; J. Escalona, Sociedad y territorio..., p. 214-215. 


\section{Cartulario}

Mucho más reveladora nos parece la vía de la redacción de cartularios. Por más que este tipo de códice pueda confeccionarse con intenciones diversas y adoptar formas muy variadas ${ }^{29}$, su función más habitual es la de servir de instrumento cómodo y articulado de consulta de la documentación del archivo, sin necesidad de recurrir a las piezas individuales. En Arlanza se elaboró un cartulario a lo largo del siglo XII, el llamado Becerro de Arlanza, que estuvo en la Biblioteca Zabálburu de Madrid hasta su desaparición durante la Guerra civil de 1936-1939. En un artículo publicado en 2001, ofrecimos una propuesta de reconstrucción del cartulario en la medida en que puede hacerse a partir de los datos publicados por Serrano en $1925^{30}$. El análisis de la estructura del cartulario permite identificar tres fases principales en su elaboración:

a) Hacia fines del reinado de Urraca o comienzos del de Alfonso VII se redactó el cuerpo principal del cartulario, que se abría con el diploma fundacional de 912, otorgado por Gonzalo Téllez, y constaba de unos 70 documentos agrupados por criterios de materia, sin orden cronológico.

b) Durante los primeros años del reinado de Alfonso VIII (probablemente durante su minoría) se añadió una segunda serie de casi 20 documentos datados entre 1135 y 1156 .

c) Finalmente, y a manera de goteo, se fue añadiendo una serie inconexa de documentos y noticias, tanto al final como en el folio de guarda al comienzo del códice.

La alteración de este folio es absolutamente crucial. En el recto aparecen copiados dos documentos datados en los años 30 del siglo XIII. En el vuelto, aparece el falso diploma de Fernán González. Parece claro que, pensando en términos estratigráficos, el diploma de Fernán González se añadió antes de rellenarse la página exterior del códice con dos documentos de escasa relevancia. Por lo tanto, el diploma falso fue incorporado al Becerro en algún momento entre comienzos del reinado de Alfonso VII y los años 30 del siglo XIII, más probablemente a comienzos del reinado de Alfonso VIII, al mismo tiempo o poco después de la adición del segundo bloque de documentos.

29. José María Ruiz Asencio, en Quintín Aldea Vaquero, Tomás Marín Martínez y José Vives Gatell (dir.), Diccionario de historia eclesiástica de España, Madrid: CSIC, 1972-1987, s. v. «Cartulario»; ver también los diferentes trabajos reunidos in: Olivier GuYOTJEANnIN, Laurent Morelle y Michel Parisse (ed.), Les cartulaires, París: École des Chartes, 1993.

30. Luciano Serrano, Cartulario de San Pedro de Arlanza (antiguo monasterio benedictino), Madrid: Junta para la ampliación de estudios, 1925; J. Escalona y P. AzcÁrate, «Una fuente "casi" perdida...». 
Pero lo verdaderamente importante es que la forma de insertar el privilegio de Fernán González, en el inicio del códice y por delante del diploma de Gonzalo Téllez, tenía la virtud de reorientar radicalmente el discurso del cartulario. Ahora, al abrir el códice, el lector se encontraba con un primer documento a toda página que proclamaba que Arlanza había sido fundado por Fernán González. Tan es así que usuarios posteriores del Becerro, como Sandoval, ante la necesidad de explicar por qué la fundación a cargo del conde venía seguida de otra por Gonzalo Téllez, redactada casi en los mismos términos, acabaron concluyendo que el tal Gonzalo era un pariente de Fernán González que había confirmado el diploma del héroe castellano como signo de reconocimiento ${ }^{31}$.

En resumen, hacia mediados del siglo XII, Arlanza reformuló su origen, pretendiendo ser fundado por Fernán González, cuya importancia como figura clave de la historia castellana iba en ascenso. En apoyo de esa idea, se elaboró un diploma falso a partir del auténtico de 912. Hacia 11601170 este texto falso se copió en el vuelto del folio de guarda del Becerro, cambiando así el discurso del códice diplomático. Probablemente por esa fecha era ya notorio que Arlanza había sido fundado por el Buen conde, y seguramente existían ya narraciones que relacionaban sus gestas con el monasterio. Esta idea salta a la luz con claridad mucho más tarde, en el mencionado pasaje de De rebus Hispaniae, y se confirma en la narrativa cronística posterior. Hacia 1255 Arlanza dio una vuelta de tuerca más, al obtener una confirmación regia del falso de 912. Finalmente, entre 1250 y 1280, el Poema de Fernán González vino a redondear el proceso, ofreciendo una versión particularmente compleja y refinada de la articulación entre leyenda y memoria histórica del monasterio.

Sin duda el éxito de Arlanza en la estrategia de anclarse a la figura del conde tuvo que influir en la decisión de otros cenobios de seguir sus mismos pasos. Parece que el primero en hacerlo fue San Millán de la Cogolla.

\section{San Millán de la Cogolla y los Votos de Fernán González}

En el caso de San Millán de la Cogolla ${ }^{32}$, es evidente que una estrategia basada en inventar una fundación a cargo de Fernán González era

31. Prudencio de Sandoval, Historias de Idacio obispo..., de Isidoro, ob. de Badajoz..., de Sebastiano, ob. de Salamanca..., de Sampiro, ob. de Astorga..., de Pelagio, ob. de Oviedo... [= Cinco obispos], Pamplona: Nicolás de Assayain (imp.), 1634, p. 308 y sq. El problema ya se le había planteado a Gonzalo de Arredondo, quien optó por hacer de Gonzalo Téllez uno de los caballeros de la hueste del conde: Mercedes VAquero (ed.), Gonzalo de Arredondo: vida rimada de Fernán González (Exeter Hispanic Texts, XLIV), Exeter: University of Exeter, 1987, p. 19.

32. Tanto para la consulta del Becerro galicano como de la colección Minguella, resultan de una utilidad excepcional las versiones digitales de los manuscritos que han sido puestas a 
totalmente inviable. Por contraste con Arlanza y con Silos, el cenobio riojano era uno de los pocos que podían alardear de ser una fundación de época visigoda perfectamente demostrable. Y para ello contaba nada menos que con la Vita Sancti Aemiliani redactada en el siglo VII por Braulio, obispo de Zaragoza, uno de los textos capitales de la hagiografía visigótica ${ }^{33}$. Pero si Fernán González no podía ser fundador de San Millán, sí podía ser favorecedor destacadísimo de un monasterio cuyo santo patrón habría colaborado eficazmente en la realización de las gestas del conde. Ese es el propósito clave del célebre diploma apócrifo conocido como los «Votos de San Millán». Conviene por tanto, en este caso, comenzar por la falsificación documental.

\section{Falsificación documental}

El diploma llamado los Votos de San Millán es una de las falsificaciones más célebres de la Edad Media hispánica, y como tal ha recibido atención por parte de diversos autores, entre los más recientes, Ubieto, Dutton, y Grande Quejigo ${ }^{34}$. Su texto se nos ha transmitido por diversas vías, de las cuales las más importantes son dos: la copia contenida en el cartulario llamado Becerro galicano de San Millán y la confirmación in extenso emitida por Sancho IV en 1289. Nos referiremos a ellas más adelante. El larguísimo preámbulo, de marcado carácter narrativo, relata cómo en 934, en vísperas de un enfrentamiento bélico entre cristianos y musulmanes, se produjeron una serie de fenómenos atmosféricos inusuales, así como otros prodigios, presagio de acontecimientos excepcionales. Con ocasión de este enfrentamiento, y para implorar el favor divino, el rey estableció un censo en favor de Santiago, a lo que el conde correspondió con otro a favor del santo riojano. En el curso de la batalla, los cristianos - que aparecen divididos en leoneses, liderados por el rey Ramiro II, y castellanos y alaveses, dirigidos por Fernán González - pudieron derrotar a sus adversarios gracias a la intervención milagrosa de dos jinetes celestiales provistos de espadas angélicas (angelico gladio). Este es el contexto de

\footnotetext{
disposición de los investigadores en el marco del monumental proyecto que está llevando a cabo la Fundación San Millán de la Cogolla: http://fsanmilla.org [consulta: 30 julio 2004].

33. Luis Vázquez de Parga (ed.), Vita sancti Emiliani sancti Braulionis Caesaraugusti episcopi, Madrid: CSIC, 1943; Santiago Castellanos, Hagiografia y sociedad en la Hispania visigoda: la «Vita Aemiliani» y el actual territorio riojano (siglo VI), Logroño: Gobierno de La Rioja, Instituto de estudios riojanos, 1999.

34. Antonio Ubieto Arteta, «Los Votos de San Millán», in: Homenaje a Jaime Vicens Vives, Barcelona: Universidad de Barcelona, 1965, t. I, p. 304-324; Brian Dutton, Vida de San Millán de la Cogolla. Estudio y edición crítica, Londres: Tamesis Books, 1967; Francisco Javier GRANDE Quejigo, Hagiografía y difusión en la vida de San Millán de la Cogolla de Gonzalo de Berceo, Logroño: Gobierno de La Rioja - Instituto de estudios riojanos, 2000.
} 
la donación piadosa, verdaderamente excepcional, que se detalla en la parte dispositiva del documento. En ella Fernán González establece un censo perpetuo anual pagadero por todas las poblaciones del territorio castellano, especificando para cada lugar — o grupo de lugares - cuál es el producto en que el pago habría de ser satisfecho, así como la parte que a cada casa corresponde aportar a san Millán, cuyos restos descansan en el monasterio, que con eufemística ambigüedad se dice ubicado «en los confines del condado» («cuius reverentissimum corpus apud confinium nostri consulatus duina [sic] disposiciones tumulatum noueramus esse [...]»).

Sin entrar en un análisis en profundidad de esta interesantísima falsificación, es preciso indicar que tiene como referente inmediato y explícito el diploma, también falso, de los Votos de Santiago, un documento de origen compostelano que a mediados del siglo XII gozaba de amplia difusión y aceptación, y que atribuía a Ramiro I el haber establecido un censo semejante para la iglesia de Santiago en razón de la supuesta intervención milagrosa del santo en favor del ejército cristiano en la batalla de Clavijo. $\mathrm{El}$ apócrifo emilianense manipula el ejemplo compostelano desplazando cuidadosamente los tiempos y los lugares. Clavijo se reubica del reinado de Ramiro I al de Ramiro II y la narración se construye sobre la de la batalla de Simancas, con la intervención conjunta de Ramiro II y Fernán González (los detalles sobre prodigios en el cielo proceden directamente de los relatos cronísticos de dicha batalla, en cuyos prolegómenos tuvo lugar efectivamente un eclipse de sol).

El apócrifo de San Millán tiene dos niveles de lectura claramente distinguibles: en un terreno práctico, supone dar cuerpo a una aspiración que, más allá de la recaudación de los votos por toda Castilla - que, aunque sabemos fue efectiva en algunos lugares, no consta que fuese ejectuada de forma general, salvo intentos muy tardíos - pretende dotar de armas más contundentes al monasterio en sus enfrentamientos jurisdiccionales con el obispado de Calahorra y con los concejos de Calahorra y Logroño; pero, en un terreno más ideológico, representa un intento muy señalado de reformular la memoria histórica del monasterio buscando vincularlo con el período fundacional de la identidad política castellana y con su figura más señera, la cual, si no puede asumir un papel de fundador, al menos desplaza sus gestas hacia el espacio riojano y establece una donación de extraordinaria envergadura en favor de la abadía. Además, el remedo de los Votos de Santiago supone poner a Castilla a la misma altura que León, y a San Millán y a su monasterio a la par nada menos que del Apóstol Santiago, como patrón de España. Las coetáneas aspiraciones de primacía por parte de Toledo brillan aquí por su ausencia ${ }^{35}$.

35. P. Henriet, «Political Struggle...». 
Ahora bien, ¿cuándo se produjo la reformulación de la historia de la abadía riojana? El problema para precisarlo es que los testimonios más antiguos de carácter diplomático proceden del cartulario llamado Becerro galicano de San Millán y de una confirmación regia relativamente tardía. Veamos ésta en primer lugar.

\section{Obtención de privilegio confirmatorio}

La primera confirmación regia que conocemos del privilegio de los votos es la otorgada en 1289 por Sancho IV $^{36}$. Precisamente una fecha tan avanzada ha hecho pensar a Grande Quejigo que hasta ese momento no existía el diploma de los votos, al menos en la forma en que ahora lo conocemos ${ }^{37}$. Pero el privilegio tiene una trayectoria más larga. Con anterioridad a esta fecha sabemos de documentos, de origen tanto regio como eclesiástico, que establecen la validez de los votos y la obligación de pagarlos, pero de manera genérica y sin aludir a ningún privilegio dado por Fernán González. Contamos incluso con un pleito de fecha tan temprana como 1216 que enfrentó a los concejos de Nájera y Logroño con San Millán sobre la cuestión de los votos, así como una bula pancarta de Inocencio III fechada en 1199, pero falsificada en San Millán en el siglo XIII, ordenando que los votos sean satisfechos sin reparos ${ }^{38}$.

Por qué hasta 1289 no se produjo la confirmación regia es una cuestión que debe quedar abierta, pero cabe hacer una observación de tipo metodológico: los privilegios confirmatorios in extenso son testimonio de una iniciativa por parte de la entidad beneficiaria, que se acerca a la cancillería regia buscando revalidar sus diplomas. El diploma en sí demuestra que esa revalidación se obtuvo. Por desgracia no tenemos constancia, en cambio, de las ocasiones en que se solicita la confirmación, pero ésta es rechazada cualesquiera que fueran las razones. Por lo tanto, cabe la posibilidad de que el monasterio hubiese intentado ganar con anterioridad una confirmación regia que no obtuvo realmente hasta 1289, en el contexto, por cierto, de un reinado especialmente propicio para ello $^{39}$.

36. Los autores que aluden a este documento se citan unos a otros como referencia, excepto Serrano, que remite a la colección Minguella, 587 (Luciano Serrano, Cartulario de San Millán de la Cogolla, Madrid: Junta para la ampliación de estudios-Centro de estudios históricos, 1930, p. XCVIII). Pero Serrano se equivoca, dando la referencia de un documento de 1290, también relativo a los votos. La colección Minguella, sin embargo, sí contiene la confirmación del privilegio falso de Fernán González por Sancho IV en 1289, pero en el número 604.

37. F. Grande, Hagiografia y difusión..., p. 255-256.

38. B. Dutton, Vida de San Millán..., p. 57.

39. Compárese este argumento con el juicio de Serrano: «Este documento fue trascrito de cualquier modo y como de contrabando en las primeras hojas del Becerro galicano que quedaban en blanco, destinadas a llevar miniado el título del mismo, el cual por ende nunca llegó a 


\section{Literatura}

Las fuentes literarias, en este caso, nos permiten ganar una perspectiva mucho más rica. En la década de los años 20 del siglo xIII, un monje emilianense llamado Fernandus escribió dos obras latinas de carácter hagiográfico, la Translatio Sancti Emiliani y el Liber miraculorum Sancti Emiliani. Para Dutton — que las editó y analizó ${ }^{40}$ — ambas demostrarían que lo esencial del episodio de los votos estaba ya formado, puesto que la primera hace alusión a su pago ${ }^{41}$ y la segunda no sólo cita la milagrosa intervención bélica de Santiago y San Millán, sino que además extracta el diploma dando un texto muy próximo al privilegio latino, del cual omite la lista de lugares y sus tributos correspondientes, pero reproduce el largo preámbulo y lo sustancial de la parte dispositiva ${ }^{42}$.

Sin embargo, la tradición manuscrita de las obras de Fernandus es muy incierta por las grandes diferencias existentes entre los dos únicos testimonios conservados en la Real Academia de la historia. La vaga referencia de la Translatio podría ser una alusión genérica a la existencia de un censo consuetudinario, en los términos en que lo proclaman otros diplomas emilianenses del siglo XIII ${ }^{43}$. En cuanto al Liber miraculorum, no se puede excluir que la inserción del extracto del diploma latino - que sólo se da en uno de los dos manuscritos - no responda a una expansión posterior del relato ${ }^{44}$. En todo caso, como primer testimonio del privilegio de los votos, el de Fernandus no es intachable.

Pisamos terreno aparentemente más seguro en la década siguiente, con la figura de Gonzalo de Berceo, a quien se debe una iniciativa de gran envergadura: nada menos que romancear y versificar la célebre Vita latina

pintarse. Pero el monasterio o no quiso, o no pudo exhibirle en las cancillerías de Fernando III ni Alfonso el Sabio; sólo en 1290 le admitió el poco concienzudo Sancho IV, incluyéndole en un privilegio por el cual le confirmaba a la letra; acto que sirvió para que los reyes sucesivos le corroboraran también sin tras averiguaciones acerca de su legitimidad.» (L. LERRANO, Cartulario de San Millán..., p. Xxxi).

40. B. Dutton, Vida de San Millán..., p. 29-59, con edición de los textos en p. 31-39, respectivamente.

41. Translatio, IX, (B. DutTon, Vida de San Millán..., p. 33-34).

42. Liber miraculorum, 8; bajo la rúbrica De offerendis Beati Emiliani (B. Dutton, Vida de San Millán..., p. 46-49).

43. Ver ejemplos en F. Grande, Hagiografia y difusión..., p. 253-257.

44. El manuscrito Emilianense, 23 (el más tardío) sólo incluye unos versos relativos al milagro de los Votos. El manuscrito Emilianense, 10, en cambio, copia casi a la letra lo sustancial del privilegio latino, pero lo hace a continuación de un pasaje en que Fernandus declara haber terminado la narración de aquellos milagros que él mismo presenció, dejando abierta la posibilidad de que quien quiera agregue nuevos episodios. Esto, obviamente, implica que el texto del privilegio pudo añadirse en cualquier momento desde la época de Fernando hasta el límite marcado por la confección del manuscrito (fechable con probabilidad dentro de la primera mitad del siglo XIII: B. DutTon, Vida de San Millán..., p. 56-57). 
de San Millán por Braulio de Zaragoza. Siguiendo una práctica hagiográfica consagrada por la tradición - y con el precedente inmediato del Liber miraculorum de Fernandus-, Berceo versionó abreviadamente la Vita y la prolongó con una selección de milagros supuestamente obrados por el santo con posterioridad al siglo VII, con la intención de mostrar una línea de continuidad desde esas remotas fechas al presente. Ahora bien, un examen en detalle permite comprobar que el verdadero objetivo de Berceo era crear un sustituto de la obra de Braulio que, conservando lo esencial de ésta, pusiera en primer plano la vinculación entre San Millán y Fernán González, precisamente a través del privilegio de los votos. La obra se inicia (1-2) con la advertencia de que hay un milagro que brilla por encima de todos los obrados por San Millán («lo más granado») y, en perfecta consonancia, tras extractar la Vita de Braulio, se inicia una detallada presentación de la tradición de los votos que ocupa casi tanto espacio como el resto de la obra. No sólo eso: la versificación romanceada de Berceo es prácticamente una amplificación, más rica en detalles efectistas, del texto latino de los votos, con la excepción de la lista de lugares y rentas, que se trunca a poco de iniciarse, por razones de espacio. Parece probable que el poeta trabajase a la vista de un texto muy semejante al latino que hoy conocemos; de hecho él mismo lo declara al referirse a el privillegio onde esto fue sacado (467b). Todo indica, pues, que Berceo conocía el diploma falso y le dio entrada en su obra precisamente porque ese era uno de sus objetivos fundamentales. Si la vida de San Millán estaba destinada a recitarse ante los peregrinos que afluían al monasterio, ¿qué mejor vehículo para divulgar la milagrosa razón del censo e insistir en la necesidad de pagarlo? Para nosotros, mejor que el incierto testimonio de Fernandus, la aportación de Berceo certifica que, al menos en la década de los años 30, la tradición del pago de votos a San Millán, que podía remontarse a fechas muy anteriores, estaba ya envuelta en un relato relacionado con Fernán González y con un desplazamiento espacio-temporal de la batalla de Clavijo.

Pero este detalle, precisamente, es peliagudo. Dutton creyó haber rescatado un vestigio textual que demostraba la circulación en San Millán de un texto latino que narraba la gesta de Fernán González en versión arlantina, pero reorientándola a favor de San Millán. Se trata de una obra de 1632 que menciona un «pergamino antiguo» o «testimonio gótico» que se hallaba en el Archivo emilianense, en el Cajón de los votos, y que hablaba de la presencia de Santiago y San Millán, «en compañía de muchos cavalleros armados con señales de cruzes en los pechos» en la batalla de Hacinas contra el rey Almanzor ${ }^{45}$. Según Dutton, esto demostraría

45. Brian Dutton, «Gonzalo de Berceo and the Cantares de Gesta», Bulletin of Hispanic Studies, XLIII, 1961, p. 197-205, en p. 203-204; también en San Millán..., p. 187. Sin embargo, 
que cuando Berceo escribía ya circulaba por San Millán un texto de los siglos XI o XII (por su escritura visigótica = «testimonio gótico»), en el que figuraban extractados algunos de los elementos clave que luego brillan en el Poema de Fernán González. Así se corroboraría la mayor antigüedad relativa del relato arlantino, que habría sido distorsionado en San Millán para crear la versión riojana de los hechos. La idea es muy sugerente, pero, por desgracia, su base no es muy firme, puesto que descansa casi exclusivamente - creemos - en el juicio del autor de 1632 sobre la escritura del texto («testimonio gótico»). Frente a ello, quedan sin resolver varios obstáculos: primero, el «pergamino antiguo» del Cajón de los votos habla de Hacinas y de Almanzor, como el Poema de Arlanza, pero Berceo sitúa la batalla en Campo de Toro y el adversario es Abderramán. Segundo, los caballeros con cruces en los pechos tienen un sabor tardío, y es poco convincente la idea de Dutton de que Berceo se hizo eco de ello al pintar a Santiago y San Millán portando cruces ${ }^{46}$. El elemento cruzado también se da en el Poema de Fernán González, pero, sobre todo, está la cuestión de la aparición conjunta de Santiago y San Millán. En el Poema arlantino actúan Santiago, San Millán y San Pelayo -que no es otro que el monje asceta confidente del conde, muerto poco antes de la batalla. Ahora bien, en una narración de este tipo, es fácil explicar la presencia de San Pelayo, pero la de Santiago y San Millán — sobre todo este último - sólo tienen plena lógica si se admite que el relato riojano funciona aquí como antecedente. El monje de Arlanza está recolocando en la zona de Lara y vinculando a su monasterio un relato con «síntomas emilianenses».

Entonces, ¿quién canibaliza a quién? Dicho de otra manera, si ponemos en cuarentena el dato paleográfico de 1632, es pefectamente posible que todo el argumento esté al revés, y que la versión de Berceo y —más de lejos - la del falso privilegio de los votos fuesen contestadas por el monje arlantino, llevándolo a su terreno, pero manteniendo elementos del relato riojano. Pero, por supuesto, esto no excluye un proceso «de ida y vuelta», es decir, que primero circulase una historia que vinculaba a Arlanza con el conde (y que podría no haber contenido nada en absoluto sobre la batalla de Hacinas); que luego en San Millán se inventase la batalla, a imitación de los Votos de Santiago, y que, finalmente, en Arlanza reciclaran también esta historia, dando como resultado la batalla de Hacinas, tal y como se

la presencia en este texto de Almanzor en vez de Abderramán lo sitúa más próximo al relato épico, conocido a través del Poema de Fernán González, y más lejano a los votos. Es posible que se trate de un texto más tardío, ya influido tanto por la tradición épica como, quizá, por la versión arlantina de la misma.

46. El texto de Berceo está en realidad más próximo al de los versos que cierran el manuscrito más tardío de los Miracula de Fernandus (RAH, Emil., 23), que también describen a los santos portando cruces. 
transmite a la Estoria de España. Como puede verse, la clave consiste aquí en no tomar la narración del Poema de Fernán González como punto de partida, sino como culminación del proceso. Volveremos sobre esto al final del trabajo.

\section{Cartulario}

Este es otro caso en que el estudio detallado de un cartulario, en nuestra opinión, permite arrojar nueva luz sobre la falsificación documental y sobre los procesos ideológicos en que ésta se enmarca. San Millán de la Cogolla contó con un cartulario elaborado a fines del siglo XI o comienzos del XII, conocido como Becerro gótico de San Millán por estar escrito en letra visigótica. Este cartulario está perdido, pero se conocen sus contenidos a través de la recopilación documental del siglo XVIII denominada «colección Minguella»" ${ }^{47}$ Gracias a ella sabemos que el diploma de los Votos de San Millán no formaba parte de este primer cartulario ${ }^{48}$. Tampoco parece que el falso atribuido a Fernán González formase parte del plan originario del segundo cartulario emilianense, el denominado Becerro galicano ${ }^{49}$. Este códice sí se conserva en la biblioteca del monasterio riojano y su análisis es del mayor interés. Como ocurría en el caso del Becerro de Arlanza, el aspecto final del Becerro galicano de San Millán es resultado de sucesivas alteraciones efectuadas sobre la obra originaria ${ }^{50}$. En su primera fase, el Becerro galicano constaba de un total de 406 documentos cuya cronología se extiende hasta 1196 . Todo este bloque presenta características muy uniformes. Se abre con una letra inicial muy decorada y mantiene en todo su desarrollo una letra muy cuidada y un formato a dos columnas, con amplios márgenes. Cada documento se encabeza con una letra inicial, de menor ornato y tamaño que la del primer documento,

47. L. Serrano, Cartulario de San Millán, p. viII.

48. La colección Minguella (núm. 34) transcribe los votos a partir del documento latino, para el cual da la signatura del archivo emilianense; igualmente indica que carece de correspondencia con el Becerro gótico, pero que sí figura en el Becerro galicano, al comienzo: «Núm. 34. Era 977, año 939: Got...; Galic. al principio. En el Cajon I, leg. $1^{\circ}$, núm. $3^{\circ}$ ». La rúbrica da la fecha de 939 - quizá por el deseo del amanuense de corregirla para ajustarla a la de la batalla histórica de Simancas - pero el texto da la era de 972, que corresponde a 934, y en ello es coherente con la copia del Becerro galicano y con la versión añadida al final de los Miracula de Fernandus.

49. Lo que invalida la mayor parte de la argumentación de Ubieto sobre la cronología de los votos. Ver A. Ubieto, «Los Votos de San Millán...», p. 309, n. 3.

50. Aunque diversos autores han aludido al Becerro galicano, no existe un estudio codicológico en profundidad del mismo. Ver L. Serrano, Cartulario de San Millán, p. ix; y B. Dutton, Vida de San Millán..., p. 1-2, quien señala brevemente algunas caracterítiscas de su proceso de elaboración, sobre todo en relación con el contexto de la inclusión en el mismo del privilegio de los votos. 
seguida de una rúbrica en rojo que indica el número del documento y lo esencial de su contenido. Esta numeración es, además, perfectamente congruente con el índice que precede a la colección documental, y que ocupa la segunda mitad de un cuaderno cosido al comienzo del códice. Se puede datar esta fase en un arco que va desde 1196 a los primeros años del siglo XIII. A partir de este momento, sin embargo, se inicia una compleja historia de adiciones y modificaciones, que - por razones de brevedad - sólo vamos a repasar aquí de manera simplificada.

Tras cerrarse la primera fase de redacción del Becerro galicano, en el folio 238 se añadió una nueva serie de documentos — divisible a su vez en dos partes por criterios paleográficos - que respetan el formato de la primera fase, aunque con claras diferencias de letra, estilísticas (en las iniciales) y en las rúbricas, que no hacen constar la numeración porque, lógicamente, estos documentos quedan fuera del índice elaborado para la primera parte. Esta serie incluye documentos del primer tercio del siglo XIII, y debió de incorporarse al Becerro en las décadas centrales del siglo. En fecha semejante o inmediatamente posterior, sin embargo, se produjo una modificación más sustancial: en la mitad del primer cuaderno que había quedado sin utilizar, es decir en los cuatro folios iniciales, se copió el privilegio de los votos, en un formato diferente, a línea tirada y sin rúbrica, aunque con una sencilla $\mathrm{S}$ inicial en rojo que concuerda estilísticamente con las que aparecen en el núcleo principal del Becerro ${ }^{51}$. Al obrar de esta manera, el Becerro galicano sufrió la misma transformación que hemos visto anteriormente para el Becerro de Arlanza: su discurso se modificó para que el lector, al abrir el códice, recibiese como primer mensaje que el monasterio de San Millán había sido especialmente favorecido por Fernán González tras los hechos milagrosos relatados. La importancia del diploma queda subrayada por el formato a línea tirada, que da paso al índice de documentos y a la colección de textos, ambos a dos columnas. De esta manera, el privilegio de los votos viene a funcionar como una suerte de prólogo a la memoria documental del monasterio ${ }^{52}$.

La historia del Becerro es muy compleja y continúa con otras series de adiciones, especialmente, con la inserción tardía de textos sueltos en diferentes puntos donde habían quedado espacios sin completar. Sin embargo, estas alteraciones, siendo importantes para la comprensión del códice, no aportan gran cosa a su significación en el proceso de elaboración de la

51. Las diferencias de formato son claras, pero quizá sea mucho decir que «fue trascrito de cualquier modo y como de contrabando», como opina Serrano (ver más arriba, n. 38).

52. Indirectamente, también sugiere que a fines del siglo XII o comienzos del XIII, cuando se puso en marcha el diseño inicial del Becerro galicano, aún no se había producido el replanteamiento de la historia del monasterio que posteriormente aconsejó iniciar el cartulario con el privilegio de los votos. 
memoria histórica emilianense. Lo verdaderamente importante es que el Becerro galicano conserva la huella de una reformulación de la historia remota de San Millán con la intención de vincularlo con las tradiciones emergentes sobre la Castilla condal, operada en algún momento antes del segundo tercio del siglo XIII. Ni el Becerro gótico ni la primera redacción del Becerro galicano presentan huellas de este proceso, lo cual, unido a las actividades literarias de Fernandus en la década de los años 20 y de Berceo en la de los 30, proporcionan un contexto suficientemente coherente sobre cuándo tuvo lugar la transformación: claramente apunta al ambiente inmediatamente anterior y posterior a la unión de los reinos de León y Castilla en $1230^{53}$.

En definitiva, el análisis del proceso de creación y difusión del privilegio de los votos de Fernán González tiene la virtud de mostrar cómo el monasterio de San Millán desarrolló un proceso similar al visto para Arlanza, reformulando su memoria histórica para entroncar con las gestas de Fernán González, y lo hizo a través de la creación literaria, la falsificación de documentos y la obtención de confirmaciones regias, así como la alteración de su cartulario. Por añadidura, la manipulación de la leyenda fernangonzaliana por parte de San Millán entra en conflicto con la no menos manipulada versión arlantina.

\section{Santo Domingo de Silos entra en escena}

La competencia entre Arlanza y San Millán se desarrolló en un plano de relativa lejanía física, puesto que ambos cenobios tenían trayectorias y ámbitos de expansión señorial diferenciados. Sin embargo, San Millán era, entre fines del siglo XII y la primera mitad del XIII, aliado firme del monasterio de Santo Domingo de Silos. Y Silos sí mantenía una rivalidad permanente con Arlanza. Si Arlanza era un monasterio de mayor antigüedad, gran presencia política y enorme implantación señorial en la comarca de Lara, Silos experimentó un crecimiento espectacular desde el último tercio del siglo XI, recortando terreno en el plano comarcal y, sobre todo, desbancando a Arlanza en dos aspectos difíciles de superar: por una parte, Silos se convirtió muy deprisa en un centro de peregrinación de gran importancia, basado en la figura milagrosa de Santo Domingo,

53. Dutton se arriesga más y propone que el privilegio fue añadido al Becerro hacia 12201225 porque lo considera una de las fuentes del Liber miraculorum de Fernandus (B. DutTon, Vida de San Millán, p. 53), pero es claro que la fuente de Fernandus no tuvo por qué ser el propio Becerro, sino más bien el documento apócrifo, que pudo copiarse en el cartulario en una horquilla cronológica más amplia. La fecha de Dutton, sin embargo, es válida como data post quem. 
empeño en el que Arlanza no brillaba por esas fechas; por otra parte, en torno a Silos fue creciendo un burgo cuyo desarrollo en el siglo XII pondría los cimientos para convertirse en la capital de la comarca a partir de la implantación del sistema de merindades menores, probablemente a fines del siglo XII, y con claridad ya en el XIII ${ }^{54}$. El pequeño villorrio arlantino de Villanueva de San Pedro no resistía la comparación con el floreciente burgo silense ${ }^{55}$.

Analizando las fuentes de manera semejante a como hemos hecho para Arlanza y San Millán, podemos observar cómo Silos, con cierto retraso, se unió a la estrategia emilianense de desviar en favor propio las líneas de discurso iniciadas por Arlanza. En este empeño se revelan, no obstante, dos rasgos peculiares. Silos se apoyó de manera muy directa en San Millán, y además hizo una utilización mucho más pragmática del nuevo discurso, tendente a imponer sus intereses en una disputa muy concreta: la que enfrentó a la abadía con el burgo de Silos durante el siglo XIII y buena parte del XIV.

\section{Literatura}

Conviene en este caso comenzar la argumentación por la faceta literaria, precisamente porque apenas podremos extraer datos de ella. En efecto, Silos contaba desde fines del siglo XI, con una Vita latina de Santo Domingo ${ }^{56}$. Sin embargo, en este texto no se alude en ningún momento a una fundación de la abadía por parte de Fernán González. Grimaldo sólo muestra interés por destacar la providencial restauración emprendida a mediados del siglo xI por Domingo y se limita a aludir a un monasterio que había sido importante, pero que había decaído hasta el extremo de casi desaparecer. El planteamiento es un tópico que se repite por doquier y no debe hacer pensar que tras ello se esconde una fundación condal: si a fines del siglo XI hubiese tenido alguna vigencia la idea de que Silos fue fundado por Fernán González, podemos estar razonablemente seguros de que Grimaldo lo hubiera mencionado. Si no lo hizo es porque dicha noción simplemente no existía en ese momento. Ni hasta bastante después, como veremos.

Al texto de Grimaldo se fueron añadiendo a lo largo del siglo XII otros lotes de milagros que vinieron a engrosar la tradición taumatúrgica del

54. Ignacio Álvarez Borge, «Merindades y merinos menores de Silos, Muñó y Castrojeriz. Notas sobre la evolución de la monarquía feudal y la organización territorial en Castilla (1200-1350)», in: III jornadas burgalesas de historia. Burgos en la plena Edad Media, Burgos, 1994, p. 655-675.

55. Sobre Villanueva de Arlanza, ver J. Escalona, Sociedad y territorio..., p. 199-200.

56. V. VALCÁRCEL, Vita dominici siliensis... 
cenobio silense, favoreciendo la llegada de peregrinos en busca de curación. En ninguno de ellos, sin embargo, hay mención alguna de Fernán González. A la altura de 1200 Silos era un santuario capaz de acoger un alto volumen de peregrinos, apoyado, sin duda, en la función del burgo como mercado y centro de comunicaciones. Es interesante, en este contexto, que en la década de los años 30 del siglo XIII —y quizá en relación con el pacto de hermandad renovado en $1236^{57}$ - otro monje emilianense, en esta ocasión Gonzalo de Berceo, se encargase de romancear y versificar la obra latina de Grimaldo, de forma análoga a como había hecho con la vida de San Millán de Braulio de Zaragoza. No vamos a entrar ahora en un estudio detenido de esta obra de Berceo $^{58}$. Baste decir que tampoco él hace la menor alusión a una relación entre Fernán González y Silos. Y no es que la obra carezca de interés. Por ejemplo, entre otras cosas, inserta algún detalle que sugiere una competencia entre Arlanza y Silos, este último con apoyos emilianenses. Nos referimos, en concreto, al episodio de la traslación de los restos de los santos Vicente, Sabina y Cristeta desde Ávila a Arlanza, en tiempos de Fernando I. Este traslado de reliquias se produjo en paralelo a la traslación de los restos de San Isidoro a León y tuvo en su momento un alto valor simbólico que el autor de la llamada Historia silense no dejó de hacer notar ${ }^{59}$.

Ya Grimaldo utilizó en favor de su propio planteamiento la misma historia, en este caso - y a pesar del tono piadoso de su discurso - al indicar que, mientras muchos abades pedían al de Arlanza fragmentos de las reliquias de los mártires, el abad Domingo no hizo lo mismo, pero para calmar la decepción de sus monjes les vaticinó que en el futuro él les daría reliquias mejores y que darían mayor prestigio al monasterio, aludiendo, según el hagiógrafo, a sus propios restos, destinados a sepultarse en Silos y ser polo de atracción de peregrinos ${ }^{60}$. No le faltaba visión de futuro a Grimaldo, ya que a la altura de 1200, Silos era un gran centro de peregrinación, mientras que Arlanza no había logrado sacar partido semejante de las reliquias de los mártires abulenses.

Esta denigración de Arlanza para reforzar a Silos se queda pequeña, sin embargo, frente a la vuelta de tuerca realizada por Berceo. En efecto, al llegar el momento de versificar este episodio, Berceo no se conforma con menoscabar las reliquias arlantinas sino que, separándose del relato

57. Miguel Carlos Vivancos Gómez, Documentación del monasterio de Santo Domingo de Silos (1255-1300), Santo Domingo de Silos: Abadía de Silos, 1995, doc. 131.

58. Brian Dutton, Vida de Santo Domingo de Silos. Estudio y edición crítica, Londres: Tamesis Books, 1978.

59. Justo Pérez de Urbel y Atilano González Ruiz-Zorrilla (ed.), Historia silense, Madrid: Aldecoa, 1959, p. 208-209.

60. V. VALCÁrcel, Vita dominici siliensis..., p. 246-248. 
de Grimaldo, convierte a Domingo en el héroe que dirige toda la operación de ida y vuelta a Ávila y lleva a Arlanza las veneradas reliquias ${ }^{61}$. En el relato de Berceo, la traslación de los mártires arlantinos se convierte en un milagro más de Santo Domingo. La intencionalidad del autor y su toma de postura en el pulso entre Arlanza y Silos está clara. Pero está igualmente claro que el monje riojano — que por esas fechas trabajaba activamente en la divulgación de los Votos de San Millán - tampoco manejaba la idea de una fundación de Silos por Fernán González. De haber sido así, sin duda hubiera utilizado ese argumento, puesto que no tuvo empacho en rectificar a Grimaldo cuando convenía a sus fines.

En definitiva, la exploración de las fuentes literarias nos permite constatar que a fines de los años 30 del siglo XIII la idea de una fundación de Silos por el Buen conde estaba aún por eclosionar. El certificado de nacimiento viene por la vía de la falsificación documental.

\section{Falsificación documental}

A lo largo del siglo XIII se falsificó en Silos un diploma que atribuía a Fernán González la fundación del monasterio, efectuada en la imposible fecha de 919. El diploma, cuyo original no se conserva, ha hecho correr ríos de tinta, entre otras cosas por los esfuerzos de algunos autores por corregir sus aspectos más rechazables con el fin de preservar su autenticidad y, con ella, la relación entre Silos y Fernán González. Destaca entre ellos Fray Justo Pérez de Úrbel, quien propuso corregir la fecha a 954, opinión que han secundado otros autores ${ }^{62}$. Sin embargo, la crítica moderna es más contundente y rechaza su validez de manera casi unánime ${ }^{63}$.

A la luz de esta revisión, el diploma se muestra como una falsificación que tiene como principal virtud definir con precisión el coto silense. En efecto, en lugar de las habituales delimitaciones vagas, basadas en los puntos cardinales, el falso de 919 nos ofrece una cuidadosa perambulación que cierra un arco en torno al burgo de Silos, con la intención de apoyar la idea de que éste fue poblado dentro de los límites jurisdiccionales de la abadía $a^{64}$. Este discurso era una pieza fundamental en la disputa que

61. B. DutTon, Vida de Santo Domingo..., p. 76-79, 265-285.

62. Justo Pérez de Urbel, Historia del condado de Castilla, Madrid: CSIC, 1945, vol. I, p. 362364; M. C. Vivancos, Documentación... (954-1254), doc. 1 y p. LII y LXII.

63. Ernesto Pastor Díaz de Garayo, «Los testimonios escritos del sector meridional de Castilla (siglos X-XI). Ensayo de crítica documental», Historia. Instituciones. Documentos, 24, 1997, p. 355-379; Manuel ZabalZa Dugue, «Escrituras de fundación de los monasterios de Arlanza y Silos. Problemas sobre su autenticidad», Boletín de la Institución Fernán González, 211, 1995, p. 333-361.

64. Sobre los topónimos, ver las notas topográficas de Marius Férotin, Recueil des chartes de l'abbaye de Silos, Paris: Leroux, 1897, doc. 1, p. 1-4, y los comentarios de Amando Represa, 
enfrentaba al monasterio y al concejo por el estatuto señorial de la villa, y queda explícito en la alegación efectuada por los representantes de la abadía con ocasión del sonado pleito de 1345: Et dezimos que esta villa de Santo Domingo es poblada dentro en los moiones que el dicho Ferrant Gonçalez e su muger donna Sancha dieron al dicho monesterio en remision de sus pecados... La larga disputa entre el monasterio y el concejo ha sido analizada en detalle por Ignacio Álvarez Borge, y el papel de las falsificaciones documentales en el proceso ha sido estudiado recientemente por uno de nosotros, de manera que no nos extenderemos en esta cuestión ${ }^{65}$.

Es más importante valorar el otro aspecto, menos pragmático, de este apócrifo, es decir, su importancia como indicador de una reformulación de la memoria histórica de la abadía. No cabe duda de que con la elaboración de este diploma, el monasterio de Silos estaba modificando su pasado y sumándose a la tendencia ya favorecida por Arlanza y San Millán, de vincularse con Fernán González y con el glorioso periodo condal. Sin embargo, en Silos - por contraste con Arlanza y San Millán - no parece que este aspecto recibiese una elaboración especial. Al menos en el frente literario, este asunto queda soterrado. La gran obra hagiográfica silense del siglo XIII, los Miraculos romanzados de Pedro Marín, no hace mención alguna de la cuestión, cuando hubiera sido fácil para el autor insertar alguna alusión que apoyase este planteamiento. Las ramificaciones del apócrifo condal tenemos que rastrearlas en terrenos más próximos a su primordial función judicial.

\section{Obtención de privilegio confirmatorio}

El monasterio de Silos hizo confirmar el falso documento fundacional en 1255. Ya hemos indicado que este es un momento peculiar, sobre todo de cara a la actividad confirmatoria de la cancillería regia. En efecto, aprovechando un periodo durante el cual Alfonso X frecuentó las tierras castellanas $^{66}$ - incluyendo alguna estancia en el propio monasterio de Silos - los monjes fueron presentando casi una cuarentena de documentos para ser revalidados en forma de privilegios confirmatorios. El falso diploma de 919 fue el último de esta serie, confirmado por el monarca el 15 de

\footnotetext{
«El burgo de Santo Domingo de Silos. De las "vilas" a la "villa" de Silos», in: Homenaje a Fray Justo Pérez de Úrbel, Santo Domingo de Silos: Abadía de Silos, 1976, t. 1, p. 309-322, quien los trabajó partiendo de la base de la validez del diploma.

65. Ignacio Áltvarez Borge, «Los concejos contra sus señores. Luchas antiseñoriales en villas de abadengo en Castilla en el siglo XIV», Historia social, 15, 1993, p. 3-27, en p. 6-11; J. EsCALONA, «Lucha política y escritura...», in: Lucha política...

66. Manuel GonZÁLeZ JiméneZ, «Itinerario de Alfonso X, rey de Castilla y León: 1252-1257», in: Carlos Reglero (coord.), Poder y sociedad en la baja Edad Media hispánica. Estudios en homenaje al profesor Luis Vicente Díaz Martín, Valladolid: Universidad de Valladolid, 2002, t. 2, p. 759-796.
} 
octubre. Este privilegio confirmatorio, sin embargo, se ha perdido y sólo conocemos su contenido gracias a su copia en el Cartulario de Silos. De nuevo, es el análisis de un cartulario el que viene a arrojar luz inesperada sobre el problema.

\section{Cartulario}

No hay noticias de que en Silos se llegase a redactar en los siglos XI-XII un cartulario en letra visigótica comparable a los perdidos de Arlanza o San Millán. Aparte de algunos catálogos documentales de diversa crono$\operatorname{logía}^{67}$, la única obra de este tipo realizada en Silos es el llamado cartulario de Silos, un códice que ha recibido hasta ahora menos atención de la que merece. Contamos con descripciones sucintas de Ferotin y Vivancos, así como un estudio monográfico de Lera que, sin embargo, no acierta a revelar todo su interés ${ }^{68}$.

Como en los dos casos vistos con anterioridad, también el cartulario de Silos fue objeto de alteraciones que modificaron sustancialmente su discurso. El análisis del códice revela que su bloque principal abarcaba en origen cuatro quiniones y se iniciaba en el que actualmente es el segundo cuaderno. En toda esta sección el formato se mantiene de manera uniforme. Los documentos se copian a línea tirada. Cada pieza se encabeza con una rúbrica en rojo y en el ángulo superior izquierdo se deja en blanco un espacio rectangular, de cuatro líneas de alto y un tercio de la longitud del renglón de ancho, destinado a la letra inicial, aunque en ningún caso llegaron éstas a a ejecutarse. Al terminar cada cuaderno se coloca un reclamo para asegurar la encuadernación en el orden correcto. Este núcleo originario contiene un total de 26 documentos; 24 son privilegios confirmatorios dados por Alfonso X en 1255, y 2 - el antepenúltimo y el penúltimo - son concesiones directas dadas a Silos por el rey en Andalucía en 1253. Todo el conjunto se puede descomponer en bloques que desvelan una lógica organizativa clara:

-4 documentos referidos a derechos generales del monasterio y derechos sobre la villa de Silos.

- 22 documentos sobre diferentes lugares del dominio, de los que los tres últimos (dos concesiones directas y una confirmación) se refieren a Andalucía.

67. M. C. Vivancos, Documentación... (954-1254), p. XxviII y sq.

68. Marius Férotin, Recueil..., p. XIII; M. C. Vivancos, Documentación... (954-1254), p. LILII; José Carlos De LeRa LaílLo: «Noticia descriptiva del cartulario gótico del monasterio de Silos. ms. 119», in: José A. Fernández Flórez (dir.), Silos. Un milenio. Actas del congreso internacional sobre la abadía de santo Domingo de Silos. II. Historia, Burgos: Universidad de Burgos, Abadía de Silos, 2003, p. 521-540. 
El plan de la obra era más ambicioso, puesto que tras el último documento de esta serie se insertó una rúbrica que reza: Aqui comiençan los privillegios de Roma, dando a entender que tras los documentos reales se pensaban registrar los de carácter eclesiástico (fol. $\left.43 \mathrm{v}^{\circ}\right)$. Sin embargo, sólo se llegó a copiar una Bula de Urbano III fechada en 1187 y que, por cierto, es otra falsificación destinada a apoyar los derechos del monasterio sobre la villa ${ }^{69}$. En este punto el plan inicial quedó interrumpido y lás ultimas 11 páginas del cuaderno, ya cosidas al resto de la obra, quedaron sin utilizar. Por esta razón se resolvió cortar los folios sobrantes - folios 6 a 9 del cuaderno-, dejando el último como guarda.

No sabemos cuánto tiempo permaneció el códice en este estado. Lo cierto es que la siguiente alteración que registra es, significativamente, la adición de un quinión en su parte inicial, modificando, como en los casos anteriormente vistos, el discurso del conjunto. Este bloque es del mayor interés. Contiene un total de cuatro documentos ${ }^{70}$ :

- La confirmación por Alfonso X en 1255 del diploma falso de fundación de Silos por Fernán González en 919.

- La confirmación de Alfonso X en 1255 de un privilegio de Alfonso VII (1155) por el que confirma y protege los términos del monasterio.

- La donación al monasterio de la martiniega de la villa de Silos efectuada por Alfonso X en 1256.

- La confirmación por Alfonso X en 1255 de un documento de Fernando III (1233) apeando los límites de Uranave, villa del dominio de Silos.

Este cuaderno antepuesto al núcleo original guarda los rasgos de formato del bloque precedente en cuanto a las rúbricas y a los espacios reservados para las iniciales, que tampoco se llegaron a ejecutar. En cambio, lógicamente, le falta el reclamo, porque fue cosido al códice de manera independiente. Además, el cuaderno no fue utilizado por completo, sino sólo hasta el fol. $8 \mathrm{r}^{\circ}$, dejando en blanco dos folios y medio.

En una tercera etapa, se añadió al final del códice una nueva serie de documentos, aprovechando el espacio libre en el último cuaderno (tres páginas) y añadiendo un quinión más. Este bloque acusa cambios formales importantes: no sólo su letra es más tardía, sino que desaparecen las rúbricas y el espacio para las iniciales, aunque sigue reservándose, cambia de proporciones: sólo abarca tres líneas de alto y el equivalente a un cuarto del ancho de caja. En cuanto a los contenidos, la serie se inicia con la confirmación por Alfonso X del fuero dado al burgo de Silos por

69. J. Escalona, «Lucha política y escritura...».

70. M. G. Vivancos, Documentación... (1255-1300), doc. 203, 178, 205 y 167. 
Alfonso VIII en $1209^{71}$, y sigue con 12 diplomas sobre lugares del dominio silense, cerrándose con un privilegio del infante Sancho IV de 1283 en que promete respetar todos los bienes y derechos del monasterio.

El proceso de adiciones termina con la inserción de un documento más, que aprovecha el espacio libre al final del cuaderno añadido al comienzo. Se cortó el folio 9 y en el espacio restante - cabalgando sobre el folio cortado - se copió la confirmación por Alfonso X de un privilegio por el que Alfonso VI habría otorgado al monasterio licencia para poblar en su coto, y que es otra falsificación destinada a surtir efecto en el pleito con el concejo. De hecho, fue utilizada en el pleito de 1345 formando un «doblete probatorio» junto con el falso de Fernán González ${ }^{72}$. Este texto tiene los rasgos formales de la ampliación anterior (sin rúbrica y con espacio para inicial más reducido) y su letra es de aspecto claramente tardío, aunque seguramente dentro aún del siglo XIII.

Por lo tanto, tenemos una trayectoria en tres fases: la primera inmediatamente después de 1255; seguida de la adición del cuaderno al comienzo, realizada poco después; y una continuación de fines del reinado de Alfonso $\mathrm{X}$ o comienzos del de Sancho IV.

El cartulario de Silos se revela tras este análisis como una obra de carácter muy diferente a los de Arlanza o San Millán. Si éstos son de orientación general, el códice silense es una recopilación monográfíca de aquellos derechos del monasterio que recibieron el respaldo regio en un arco cronológico bastante reducido. Pero, sin duda, el aspecto que marca más las distancias con los otros dos cartularios estudiados es su clarísimo tono argumentativo. Este carácter puede estar menos claro en su redacción inicial, dado que su estructura varió en el tiempo y, sobre todo, que el plan originario de la obra se vio interrumpido nada más iniciar el apartado de bulas pontificias. Sin embargo, es evidente que en algún momento dentro del reinado de Alfonso X se decidió modificar el cartulario en un sentido que refuerza enormemente su valor como alegato a favor del monasterio. Basta para cerciorarse de ello con leer seguidas las rúbricas de los documentos del cuaderno antepuesto al comienzo del códice:

- Doc. 1: Privilegio del cuende Fernan Gonçalvez, que nos dio la villa e es seellado con seello de çera.

- Doc. 2: Privilegio del emperador don Alffonso que nos otorgo la villa e el termino et es seellado con çera [en el margen, de letra posterior: Con este privilegio nos da la villa de Silos].

71. Otro documento de importancia capital en la pugna con el concejo (ver J. Escalona, «Lucha política y escritura...»).

72. Comentario en J. Escalona, ibid. 
- Doc. 3: Privilegio del rey don Alffonso fijo del rey don Ferrando que nos dio toda la marçatga [sic] de la villa de Sancto Domingo e es seellado con plomo.

- Doc. 4: Privilegio del termino de Uranaf que confirmo el rey don Ferrando et es seellado con plomo.

La inserción a continuación del falso de Alfonso VI — efectuada a fines del siglo XIII - da una vuelta de tuerca adicional:

- Doc. 5: Sin rúbrica. Una cabecera de mano posterior indica: Privilegio del emperador don Alffonso que nos mando poblar la villa de Silos.

En definitiva, el cartulario de Silos pertenece a un momento conflictivo en que los intereses señoriales del monasterio están en juego, y pretende ser una herramienta para su defensa. En este sentido, debe ser puesto en paralelo con la redacción en los años 80 del siglo XIII de los Miraculos romanzados de Pero Marín, obra que remata el ciclo hagiográfico medieval silense y que utiliza la figura de Alfonso X para potenciar el valor de la abadía como centro de peregrinación, efectuando, de paso, algunos interesantes cruces con la documentación del archivo, como ocurre con la célebre narración que proporciona un contexto milagroso para la concesión del privilegio de la martiniega de la villa de Silos, arriba mencionado ${ }^{73}$.

En todo caso, debe destacarse que en la argumentación que pone en pie el cartulario de Silos, la cuestión de la reformulación de la memoria de la abadía y la conexión con el ciclo épico de Fernán González es mucho menos importante que el discurso tejido en torno a los derechos señoriales sobre la villa, fuesen cuales fuesen sus fuentes. Aquí, el Buen conde no parece ser sino un recurso más, cuya eficacia legitimadora había quedado demostrada por su empleo en Arlanza y San Millán, y que los monjes silenses movilizaron como una herramienta más. Pero no dio lugar a un gran esfuerzo de revisión del pasado y, de hecho, las fuentes literarias no acusan el menor impacto, a diferencia de los dos casos anteriores.

73. Ver Amaia Arizaleta, «La memoria del monarca: Pero Marín, testigo de Alfonso X (Miraculos romançados, 4)», in: Carlos Heusch (ed.), De la lettre à l'esprit des textes médiévaux espagnols. Hommage à Michel Garcia, Paris: Le Manuscrit, 2006 (kalamos, 1). Agradecemos a la autora habernos permitido utilizar el texto de su artículo antes de la publicación. 


\section{Conclusión: reinvención del pasado y falsificación documental}

A manera de recapitulación, volvamos a la matriz en que hemos basado el análisis.

\begin{tabular}{|c|c|c|c|}
\hline & Arlanza & SAN MiLláN & SILOS \\
\hline Litteratura & $\begin{array}{l}\text { Jiménez de Rada } \\
\text { Poema de Fernán } \\
\text { González }\end{array}$ & $\begin{array}{l}\text { Fernandus } \\
\text { Berceo }\end{array}$ & $\begin{array}{l}\text { Grimaldo } \\
\text { Berceo } \\
\text { Pero Marin }\end{array}$ \\
\hline $\begin{array}{l}\text { Falsificación } \\
\text { documental }\end{array}$ & $\begin{array}{l}\text { 912: Fundación por } \\
\text { F. González }\end{array}$ & $\begin{array}{l}\text { 934: Votos de San } \\
\text { Millán }\end{array}$ & $\begin{array}{l}\text { 919: Fundación por } \\
\text { F. González }\end{array}$ \\
\hline $\begin{array}{l}\text { Confirmación } \\
\text { regia }\end{array}$ & 1255, Alfonso X & 1289, Sancho IV & 1255, Alfonso X \\
\hline $\begin{array}{l}\text { Redacción de } \\
\text { cartularios }\end{array}$ & Becerro de Arlanza & $\begin{array}{l}\text { Becerro galicano de } \\
\text { San Millán }\end{array}$ & Cartulario de Silos \\
\hline
\end{tabular}

Como se puede apreciar, los cuatro ejes de indagación que sugeríamos al principio permiten otras tantas aproximaciones a cada monasterio, aunque produzcan resultados desiguales. Así, las obras literarias dan pistas muy valiosas en el caso de San Millán (problemáticas en las obras de Fernandus, sustanciosas en la de Berceo), y también en el de Arlanza, aunque la tardía datación del Poema de Fernán González requiere un manejo prudente que, sin embargo, se compensa en parte con la madrugadora referencia de Jiménez de Rada. En cambio, en el caso de Silos, las fuentes literarias no presentan huellas del proceso de falsificación documental asociado a Fernán González. Tan sólo dan alguna pista sobre la relación San Millán-Silos y su enfrentamiento con Arlanza. Pero esto es un dato valioso en sí mismo, como se ha visto.

En el terreno de la falsificación documental, hemos podido apreciar cómo la iniciativa parece haber correspondido a Arlanza en fechas tempranas (y ello seguramente implica un desarrollo narrativo paralelo no documentado). A imitación de esta estrategia, San Millán habría desarrollado tanto una línea narrativa propia destinada a desplazar hacia el ámbito riojano las gestas condales, como una falsificación documental que daba nuevas alas a una tradición seguramente mucho más antigua sobre el derecho de San Millán a percibir unos censos más o menos generalizados. A imitación de San Millán, Silos parece haber ensayado la misma estrategia con fines diferentes, para apoyar sus reivindicaciones jurisdiccionales. 
Tanto Arlanza como Silos aprovecharon el peculiar contexto político de 1255 para obtener de Alfonso X privilegios confirmatorios de sus apócrifas fundaciones. En cambio San Millán se demoró hasta otro momento no menos propicio, como es el reinado de Sancho IV, sin que por ahora podamos dar una explicación satisfactoria a este retraso respecto de la época de elaboración del documento falso, que tiene que ser anterior a su traslado al Becerro galicano, que situamos en los años centrales del siglo XIII.

Sin duda son los cartularios los que ofrecen pistas más valiosas, entre otras cosas, porque se trata de un tipo de fuente que rara vez se pone en juego con estos objetivos. Aunque sea con carácter exploratorio, y a la espera de una investigación de mayor detalle, hemos sondeado tres cartularios de tamaño, características y funcionalidad diferentes, pero unidos por dos rasgos comunes: a) los tres llegaron a albergar copias de documentos falsificados que ponían en relación a sus respectivos monasterios con la figura de Fernán González; b) los tres sufrieron varias fases de elaboración, destacando que en los tres casos partes redactadas con posterioridad a sus núcleos originarios fueron adjuntadas al comienzo, modificando de manera sustancial sus discursos. En los tres casos, estos elementos añadidos tienen como componente principal documentos falsos de temática condal. Sin embargo, su valor no es el mismo en los tres. En el caso de Arlanza, un sólo documento, antepuesto a la auténtica fundación, sirve para reformular los orígenes del monasterio en un momento crucial de su historia; es casi seguro que un paso así sólo pudo darse en combinación con algún tipo de relato que enlazaba al conde y al monasterio y podría constituir el antecedente perdido del Poema de Fernán González. En el caso de San Millán, igualmente, el privilegio de los votos se antepone al cartulario preexistente y con ello basta para formular su reivindicación de un pasado glorioso en el siglo $\mathrm{x}$, completando una memoria histórica del monasterio en que la venerable fundación de época visigoda quedaba demasiado distante; en este caso las fuentes literarias sí permiten apreciar cómo la falsificación y la alteración del cartulario corren en paralelo con la formulación de discursos narrativos articulados y destinados a una audiencia en expansión. En cambio, en el caso de Silos, lo que se antepone en el cartulario es un conjunto de documentos encabezado, sí, por el de Fernán González, pero dentro de un discurso que no tiene por objetivo tanto reconstruir la memoria histórica de la abadía como acumular argumentos en favor de sus posturas en la arena judicial. Significativamente, las fuentes literarias silenses no vienen a reforzar la supuesta fundación condal, mientras que sí lo hacen con otros textos clave como la concesión de la martiniega de la villa en 1256. 
En términos cronológicos parece que el proceso puede ser ordenado de esta manera:

- En fecha que no podemos precisar, fueron tomando cuerpo una serie de relatos sobre las gestas del conde Fernán González, como parte de un corpus más amplio de narraciones sobre el pasado castellano que hacia mediados del siglo XII tenían difusión suficiente para justificar una iniciativa monástica por apropiarse de dichas tradiciones.

- En algún momento durante el tercer cuarto del siglo XII Arlanza dio ese paso al vincularse a la figura del conde y repensar su origen con Fernán González como fundador.

- Entre 1220 y 1240, San Millán desarrolló una estrategia comparable que a mediados de siglo había producido consecuencias literarias y documentales.

- Hacia mediados del siglo XIII, Silos secundó a su aliado riojano deslizándose, con menos entusiasmo, por un camino ya suficientemente experimentado. La falsa fundación por Fernán González parece aquí más una simple imitación de estrategias exitosas que un verdadero proceso de reinvención de la historia silense.

Ahora bien, es preciso no dejar caer en saco roto un hecho incontestable: aunque las evidencias documentales apuntan a Arlanza como el iniciador de esta trayectoria, la abadía arlantina también produjo alguno de los testimonios más tardíos de la misma. Por una parte está su aportación de materiales para la redacción de la Estoria de España de Alfonso X, en la década de los años 70 del siglo XIII, lo que consagró definitivamente la visión arlantina de la historia de la Castilla condal, al menos en la línea de tradición históriográfica de la Primera crónica general, bastante diferente de la promovida por la Crónica de 1344. Por otra parte, lógicamente, está el Poema de Fernán González. No cabe duda de que esta peculiar obra tiene que haber tenido antecedentes narrativos (entre otros, los que permitieron a Rodrigo Jiménez de Rada establecer la relación entre Arlanza y el conde en los años 40 del xIII), pero su redacción, datable entre 1250 y 1270, debe ser situada en su propio contexto, y no sólo en el de sus desarrollos precedentes.

Desde esta perspectiva, el Poema de Fernán González puede ser interpretado como parte de una reacción arlantina ante San Millán y Silos, reivindicando una tradición fernangonzaliana que consideraban propia. Así se podría explicar que el Poema de Fernán González contenga una versión de la batalla de Hacinas donde se dan cita Santiago, San Pelayo y San Millán en apoyo del ejército castellano. Santiago y San Millán sólo tienen pleno sentido en la pseudo-batalla de Clavijo urdida en relación con los votos. Si existió previamente una narración arlantina del mismo episodio, ubicándolo en Hacinas, la versión del Poema suena más bien como un intento 
de llevar las aguas a su cauce, recuperando la figura de Fernán González de manos de San Millán.

Hay más indicios que sugieren que la aportación arlantina de materiales para la Estoria de España se produjo en un contexto de rearme de Arlanza, cuando la abadía intensificaba sus esfuerzos en torno a la figura del conde. Luciano Huidobro publicó algunas noticias procedentes de un Compendio historial - hoy por desgracia ilocalizable - compuesto en 1563 por el monje arlantino Fray Juan de Pereda, quien tuvo acceso a una gran cantidad de material textual hoy perdido. Por más que Fray Juan pudiese transmitir datos erróneos y que la presentación de la información por parte de Huidobro deje mucho que desear, aparecen en esta publicación algunos detalles que Pereda difícilmente pudo inventar. Así - siempre según el artículo de Huidobro- Pereda relataba cómo en 1274 tuvo lugar el solemne traslado de los restos de Fernán González de una ermita próxima que estaba en ruinas a la abadía. Esta ermita debe ser la iglesia de San Pelayo o San Pedro el Viejo, considerada el emplazamiento original del monasterio de Arlanza hasta la construcción del gran edificio románico en el siglo XI. Lo llamativo es que (siempre según Pereda en versión de Huidobro) los restos del conde fueron colocados... jen un catafalco en el centro de la nave principal de la iglesia de Arlanza, en una posición tan prominente que estorbaba para los actos de culto, por lo que en el siglo XIV se optó por desplazarlo a un lateral ${ }^{74}$ ! Sin duda una iniciativa como ésta tenía una carga simbólica extraordinaria como reivindicación de una vinculación entre el monasterio y el conde, capaz de poner en su sitio a cualquier otro que aspirase a beneficiarse de su influjo. Y no era el único caso, porque, por esas fechas, la pugna por presentarse como lugar de descanso de los principales personajes de la épica castellana afectaba también a otras narraciones, como la de los Infantes de Lara, e implicaba no sólo a monasterios como San Millán y Silos, sino también a concejos como Salas de los Infantes, por no hablar de los linajes nobiliarios que modificaron sus genealogías para insertar a tan prestigiosos ancestros ${ }^{75}$. Claramente, había todo un «capital simbólico» por el que competir.

74. Luciano Huidobro, «El monasterio de San Pedro de Arlanza y su primer compendio historial inédito», Boletín de la Comisión Provincial de Monumentos de Burgos, 1, 1922-1925, p. 199207. El bajón de categoría asociado a este cambio de ubicación probablemente requería una explicación. Así, la Vida rimada de Fernán González, compuesta por Gonzalo de Arredondo a comienzos del XVI imagina un final en que el conde al presentir su muerte, elige ser enterrado en Arlanza, pero advierte que desea ocupar una posicion discreta, y dejar los lugares de honor para quienes valiesen más que él. Q. VAQUero, Vida rimada..., estrofas 237-239, p. 55.

75. J. Escalona, «Épica, crónicas y genealogías...». 